\title{
Study on the Gap Flow Simulation in EDM Small Hole Machining with Ti Alloy
}

\author{
Shengfang Zhang, Wenchao Zhang, Yu Liu, Fujian Ma, Chong Su, and Zhihua Sha \\ School of Mechanical Engineering, Dalian Jiaotong University, Dalian 116028, China \\ Correspondence should be addressed to Wenchao Zhang; traum525@gmail.com
}

Received 10 July 2016; Accepted 30 January 2017; Published 28 June 2017

Academic Editor: Gianfranco Palumbo

Copyright (C) 2017 Shengfang Zhang et al. This is an open access article distributed under the Creative Commons Attribution License, which permits unrestricted use, distribution, and reproduction in any medium, provided the original work is properly cited.

In electrical discharge machining (EDM) process, the debris removed from electrode material strongly affects the machining efficiency and accuracy, especially for the deep small hole machining process. In case of Ti alloy, the debris movement and removal process in gap flow between electrodes for small hole EDM process is studied in this paper. Based on the solid-liquid two-phase flow equation, the mathematical model on the gap flow field with flushing and self-adaptive disturbation is developed. In our 3D simulation process, the count of debris increases with number of EDM discharge cycles, and the disturbation generated by the movement of self-adaptive tool in the gap flow is considered. The methods of smoothing and remeshing are also applied in the modeling process to enable a movable tool. Under different depth, flushing velocity, and tool diameter, the distribution of velocity field, pressure field of gap flow, and debris movement are analyzed. The statistical study of debris distribution under different machining conditions is also carried out. Finally, a series of experiments are conducted on a self-made machine to verify the 3D simulation model. The experiment results show the burn mark at hole bottom and the tapered wall, which corresponds well with the simulating conclusion.

\section{Introduction}

Titanium (Ti) alloy is an excellent candidate for aerospace, biomedical applications and ocean development owing to the high specific strength and excellent corrosion resistance. In a traditional hole drilling the high tensile strength and low thermal conductivity of $\mathrm{Ti}$ alloy can result in a large machining force, high machining temperature, high tool wear, and poor accuracy, especially for deep small hole machining.

EDM could remove the material by spark erosion, which produces the local high temperature to melt and vaporize the material at the workpiece surface. During EDM process [1], the tool electrode does not contact the workpiece, which results in the tiny machining force. Therefore, the deformation is small and the machining accuracy is excellent, which is suitable to manufacture the deep small hole on Ti alloy. In general, a lot of debris is generated during EDM process in small deep hole. The debris could affect the dielectric strength of gap and discharge stability during EDM process, which results in the concentrated discharge and low machining efficiency [2]. The debris is also likely to form secondary discharge between the tool and wall, which results in the tapered side wall of hole. Even though the flushing is introduced to remove the debris from the machining gap, because of the nonthoroughness of debris removal, it is difficult to obtain satisfactory machining accuracy [3]. So the debris removal process is one of the most important challenges for EDM application in deep small hole machining.

There are many researchers studying the debris removal mechanism in EDM process for deep small hole. Koenig et al. built a mathematical model of bottom gap flow field with flushing and calculated the pressure and velocity field [4]. Masuzawa et al. simulated the flow field with flushing and the debris distribution in the gap [5]. Takeuchi and Kunieda simulated the velocity field of debris and took the dielectric movement and bubble expansion into consideration [6]. Allen and Chen investigated the material removal for micro-EDM on molybdenum by using a Matlabbased thermonumerical model, which simulated single spark 


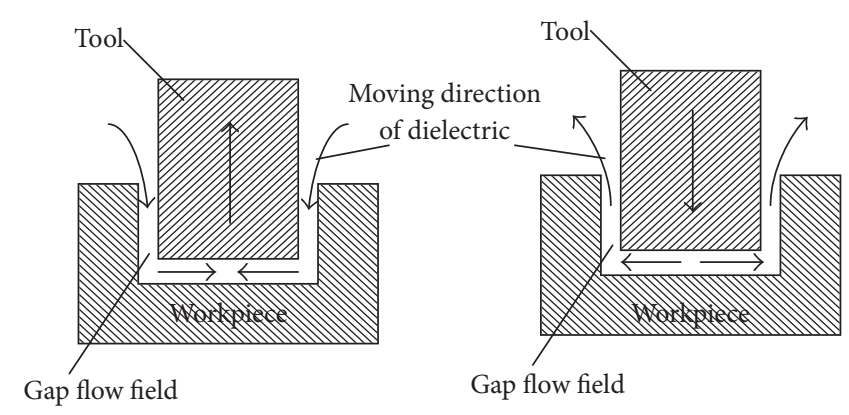

(a) Tool up

(b) Tool down

FIGURE 1: Schematics of tool movement model.

discharge process [7]. Wang et al. simulated the flow field in EDM machining, and debris aggregated at the corner increased the concentrated discharging, which destroyed the edge of tool [8]. Xie et al. simulated the holes array with ultrasonic assisted in EDM and concluded that the ultrasonic vibration of tool had influence on the debris exclusion from discharge gap [9]. Cetin et al. investigated the effects of electrode jump parameters on machining speed and depth experimentally in linear motor equipped electrical discharge machining [10]. Wang et al. made researches on the debris and bubble movement with Fluent and summarized that the bubble generated at the bottom was the main factor to expel the debris. But the expelling effect became weak when the bubble reached the side gap [11]. Kong et al. simulated the motion of debris with bubbles under with and without ultrasound [12]. Mastud et al. conducted simulations on computational modeling of the debris motion and its interaction with the dielectric fluid under low-amplitude vibrations imparted via a magnetorestrictive actuator [13]. Mullya and Karthikeyan analyzed the fluid flow along the narrow gap of microelectrodischarge-milling process for different machining conditions by computational fluid dynamics simulation [14].

For above available results, most researchers only developed the single discharge machining models. Actually, the debris is continuously generated in EDM process. Besides, the flow disturbation generated by the movement is not considered. So the debris movement process for multicycle discharge with tool movement in EDM is not fully understood.

This paper develops a mathematical model that considers tool movement in solid-liquid two-phase gap flow field and a $3 \mathrm{D}$ model to simulate the tool movement and debris generation when the tool electrode conducts self-adaptive movement. Besides, the debris is generated continuously in the gap between the tool and workpiece. Such simulation is much closer to the real machining process.

\section{Debris Generation and Tool Movement in EDM}

EDM as a nontraditional machining method uses the electrothermal effect of pulsed spark discharge between tool and workpiece to remove the material in dielectric fluid. When the distance between the electrodes is reduced to $10^{2} \mu \mathrm{m}$, the electric field intensity between electrodes becomes greater than the strength of the dielectric. The voltage applied breaks down the dielectric and induces the plasma channel between two electrodes. Then the power supply instantaneously releases the energy through the channel, which generates the temperature of about $1 \times 10^{4 \circ} \mathrm{C}$ and a very high pressure in a local minimal area [15]. Consequently, a small quantity of metal is directly molten or even vaporized due to the heat effect. Once the voltage stops, the spherical debris is removed, and microdischarging craters appear on both tool and workpiece surfaces. Simultaneously, the insulating property of dielectric is restored.

As the process going on, a certain amount of material will be removed and the debris will be generated continuously. The accumulative debris can influence the break down process and machining efficiency. During the small hole machining process, the debris is regularly swept away from the machining region by flow of flushing. However, in a deep small hole machining, the flushing effect on debris at the bottom of the hole becomes weak. In addition to the flushing, the tool motion could facilitate the debris removal. As the operation progresses, the servo mechanism controls tool to make self-adaptive movement and maintains a proper gap. Meanwhile the servo movement of tool generates the disturbation to the gap flow. When the tool moves up, a negative pressure zone forms at the bottom and fresh dielectric is drawn into the gap, which lowers the concentration of debris, as shown in Figure 1(a). On the contrary, a positive pressure zone forms when the tool moves down, just as shown in Figure 1(b), the debris spreads to the surroundings, and a little debris is carried away with the fluid into the fresh dielectric. During the debris removal process, the major factor to drive debris is the drag force, for the gap flow can be seen as a solidliquid two-phase flow.

\section{Gap Flow Mathematical Model of Solid-Liquid Two-Phase Flow}

3.1. Drag Force Analysis. In solid-liquid two-phase flow field, the drag force of particles $F_{d}$ is the most basic form of interaction between particles and fluid. In order to obtain the 


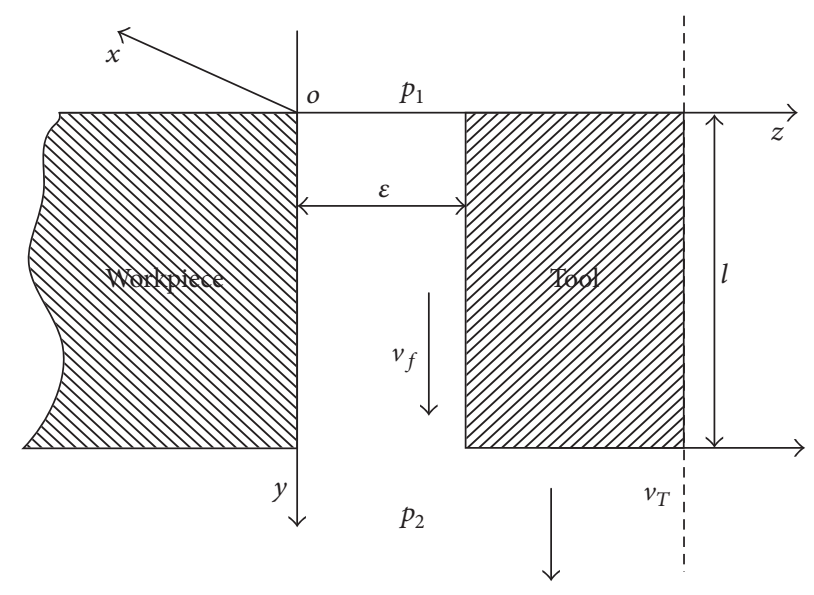

FIGURE 2: Schematics of interelectrode gap.

drag force equation of solid-liquid two-phase flow, this paper assumes the conditions as follows:

(1) The particle is considered to be spherical.

(2) The particle reflects back when colliding with the wall or other particles.

(3) The ambient temperature and machining region temperature are considered as a constant, no heat exchanges.

(4) The fluid field is considered to be infinite, inviscid, and uncompressible.

(5) There is no friction con the inner wall of hole.

Figure 2 shows a partial view of the side gap. The tool and workpiece are considered as two parallel plates. Only the tool moves during simulation. Therefore, the velocity difference is generated in the gap, which results in the pressure difference along the depth ( $y$-axis) changes. $v_{T}$ and $v_{f}$ are the tool speed and liquid speed, respectively.

Naviers-Stokes equation can be simplified as follows:

$$
-\frac{1}{\rho} \frac{d p}{d y}+\lambda \frac{d^{2} v_{f}}{d z^{2}}=0
$$

where $\rho$ is the fluid density, $p$ is the fluid pressure, $\lambda$ is coefficient, and $v_{f}$ is the fluid velocity along $y$-axis. The pressure $p$ along the $y$-axis declines uniformly, which can be presented as

$$
\frac{d p}{d y}=-\frac{\Delta p}{l}
$$

where $\Delta p=p_{1}-p_{2}$. When the tool moves down, $v_{T}$ points to the positive $y$-axis and $\Delta p$ is less than 0 . When the tool moves up, $v_{T}$ points to the negative $y$-axis and $\Delta p$ is greater than 0 . By combining (1) and (2), we get the equation

$$
\frac{d^{2} v_{f}}{d z^{2}}=-\frac{\Delta p}{\mu l},
$$

where $\mu$ is dynamic viscous coefficient of fluid. By integrating (3), we get the fluid speed as

$$
v_{f}=-\frac{\Delta p}{2 \mu l} z^{2}+C_{1} z+C_{2},
$$

where $C_{1}$ and $C_{2}$ are coefficients; given that the tool has a speed of $0.01 \mathrm{~m} / \mathrm{s}$, finally the boundary conditions are listed as follows:

$$
\begin{aligned}
z & =\varepsilon, \\
v_{f} & =0.01, \\
z & =0, \\
v_{f} & =0,
\end{aligned}
$$

where $\varepsilon$ is the $z$-axis position. $C_{1}$ and $C_{2}$ can be solved by combing (4) and (5).

Considering the impact of flushing on fluid velocity, the fluid velocity $v_{f}^{\prime}$ is shown as

$$
v_{f}^{\prime}=v_{f}+v_{t}
$$

where $v_{t}$ is the speed at a certain position in the case of flushing and can be solved by unsteady flow equation (7) of solid-liquid two-phase flow.

$$
\begin{aligned}
& \frac{\partial \rho}{\partial t}+\frac{\partial}{\partial y}\left(\rho v_{t}\right)=0, \\
& \rho\left(\frac{\partial v_{t}}{\partial t}+v_{t} \frac{\partial v_{t}}{\partial y}\right)=-\frac{\partial p}{\partial y}-\rho g \cos \theta-\frac{P}{A} \tau_{w}, \\
& \frac{\partial}{\partial t}\left[\rho\left(e+\frac{v_{t}^{2}}{2}\right)\right]+\frac{\partial}{\partial y}\left[\rho v_{t}\left(h+\frac{v_{t}^{2}}{2}\right)\right] \\
& \quad=\frac{1}{A}\left(\frac{\partial q_{e}}{\partial y}-\frac{\partial \omega}{\partial y}\right)-\rho v_{t} g \cos \theta,
\end{aligned}
$$

where $g$ is acceleration of gravity, $\tau_{w}$ is the average shearing stress of the wall, $e$ is the thermal energy of unit mass, $h$ is 


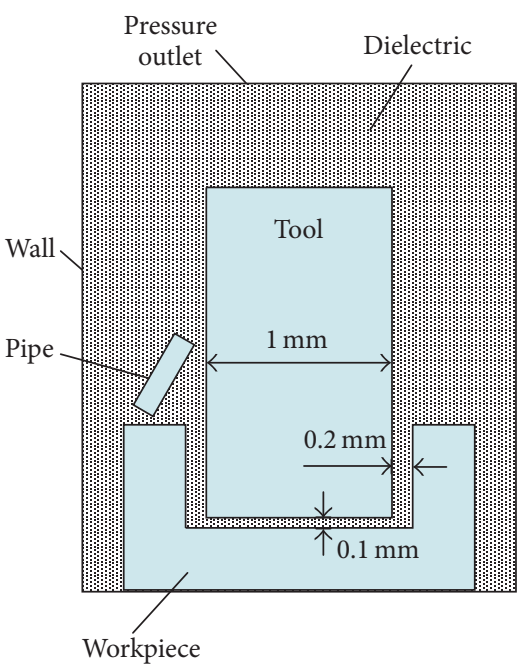

(a) Boundary conditions

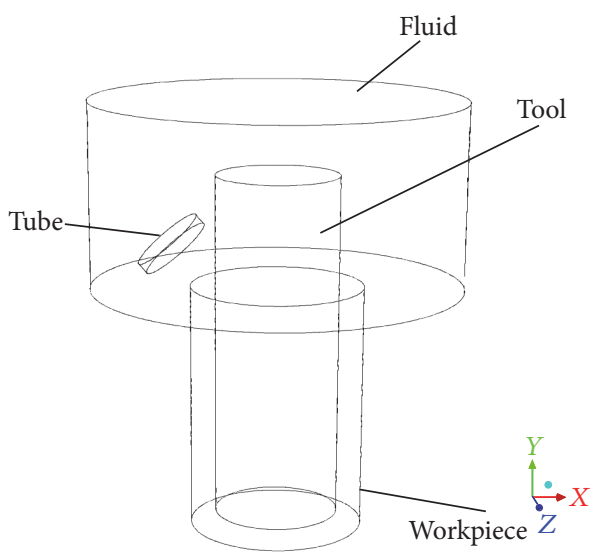

(b) 3D model

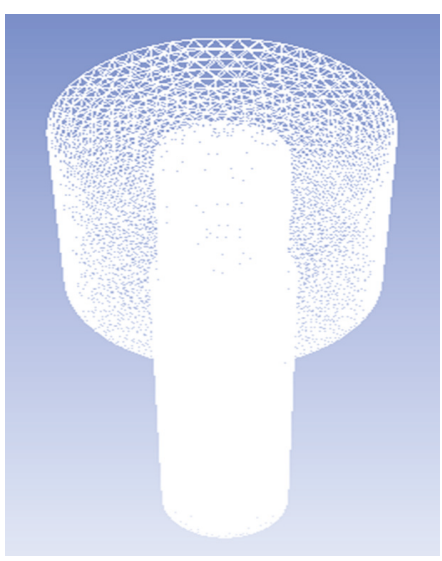

(c) 3D meshed model

FIGURE 3: The schematics of 2D boundary conditions and 3D meshed model.

the enthalpy, $q_{e}$ is the heat transfer rate, and $\omega$ is the power. Bruce et al. summarized an equation to get the drag force on the particles, which can be presented as [16]

$$
F_{d}=6 \pi \mu r_{p}\left(v_{f}^{\prime}-v_{p}\right) \sigma,
$$

where $r_{p}$ is the radius of particle, $v_{p}$ is the particle velocity, and $\sigma$ is the correction factor. Each step of $v_{p}$ can be solved by iterating equations. Initially, the actual drag force equation of solid-liquid two-phase flow considering the effect of tool movement can be shown as follows:

$$
F_{d 0}=6 \pi \mu r_{p}\left[\frac{\Delta p_{0}}{2 \mu l}\left(\varepsilon \cdot z-z^{2}\right)+v_{t 0}-v_{p 0}\right]
$$

as $F=m a, m=(4 / 3) \pi r^{3} \rho$, and the initial acceleration of particle $a_{p 0}$ can be presented as

$$
a_{p 0}=\frac{9 \mu\left[\left(\Delta p_{0} / 2 \mu l\right)\left(\varepsilon \cdot z-z^{2}\right)+v_{t 0}-v_{p 0}\right]}{2 r_{p}^{2} \cdot \rho_{p}}
$$

where $\rho_{p}$ is particle density. After several iteration, the $n$th time step of particle velocity $v_{p(n)}$ and moving distance $S_{p(n)}$ can be solved as follows:

$$
\begin{aligned}
& v_{p(n)}=a_{p(n-1)} \cdot t, \\
& S_{p(n)}=\sum_{i=1}^{n} S_{p(i)}=\sum_{i=1}^{n} v_{p(i)} t .
\end{aligned}
$$

From the equations above, we deduce that when the depth of gap $(y)$ increases, the fluid velocity $v_{f}^{\prime}$ and drag force $F_{d}$ decline and the debris velocity $v_{p}$ and moving distance $S_{p}$ decrease. On the contrary, if flushing velocity $v_{t}$ increases, the fluid velocity $v_{f}^{\prime}$ and drag force $F_{d}$ increase and the debris velocity $v_{p}$ and moving distance $S_{p}$ increase.
3.2. Simulating Model for the Interelectrode Gap Field. Figure 3 shows the simulation model for the interelectrode gap flow field in EDM. The side and bottom gap are set to 0.2 and $0.1 \mathrm{~mm}$, respectively. The debris generated in single pulse is distributed in a random position at the bottom with the macrofunction provided by Fluent [17].

The boundary conditions are shown in Figure 3(a). The interface boundary is applied, because the flushing tube and working liquid need to exchange data. The upper boundary condition is the pressure outlet and rest boundaries are the walls as default. Figure 3(b) presents the 3D model, where the flushing is ejected from the tube outlet into the gap. In Figure 3(c), the machining zone is considered as a $3 \mathrm{D}$ cylinder model, which is established and meshed in the Gambit. The meshed model is imported into Fluent. The secondary development interface UDF module is used to simulate the debris removal process, because the shape of flow field is constantly changing in with the servo movement of the tool.

This paper assumes simulation cycle and discharge cycle at $0.02 \mathrm{~s}$ and $20 \mu \mathrm{s} .1000$ discharges occur during the simulation process. Only half of the discharges are effective. The initial count of debris is 2550 at the bottom, which distributes into three layers and each layer uniformly contains 850 debris. During the simulating process, each discharge generates 30 debris in the random position, and the ratio of Ti alloy debris to $\mathrm{Cu}$ debris is 2 to 1 , of which $\mathrm{Ti}$ alloy and $\mathrm{Cu}$ debris are in blue and red, respectively [18]. During the process, 17550 debris are generated. The simulating parameters are listed in Table 1. Flushing velocity is obtained from the previous experiment.

\section{Simulation Results and Analysis}

4.1. Impact of Tool Movement on Gap Flow Field without Flushing. Without flushing, the simulation results of $1 \mathrm{~mm}$ 


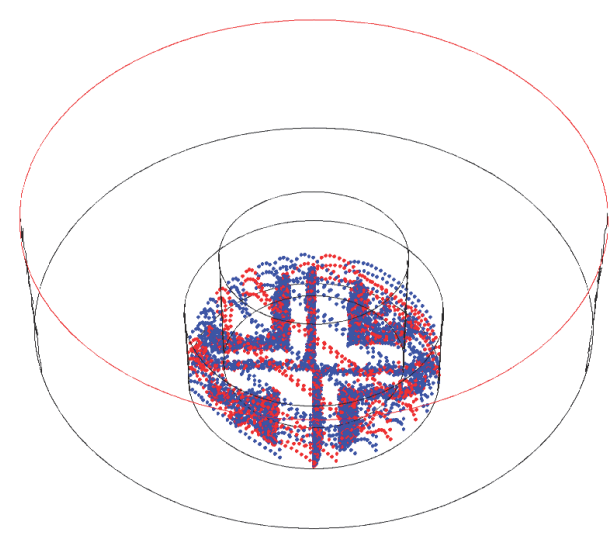

(a) After half a period

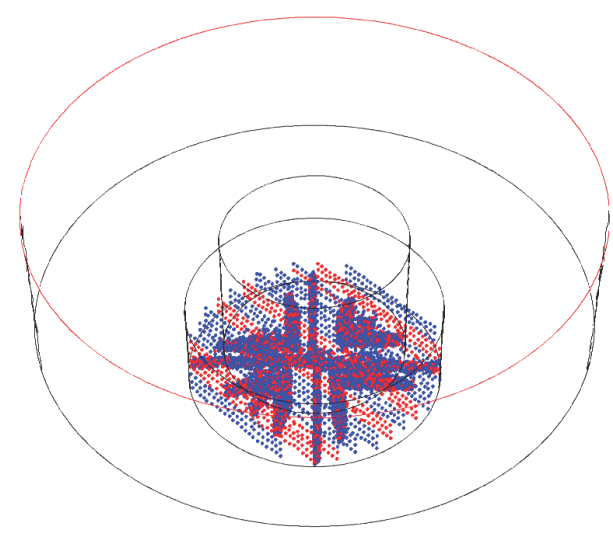

(b) After one period

Figure 4: Gap flow field with $0.5 \mathrm{~mm}$ deep hole.

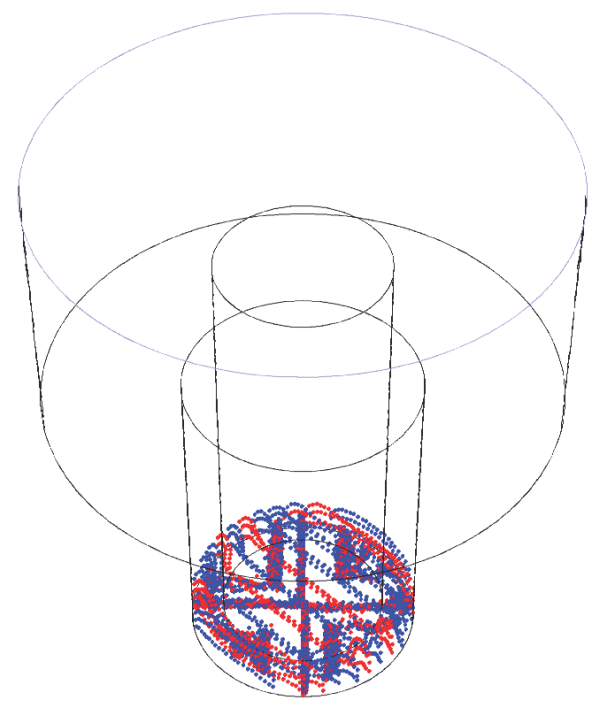

(a) After half a period

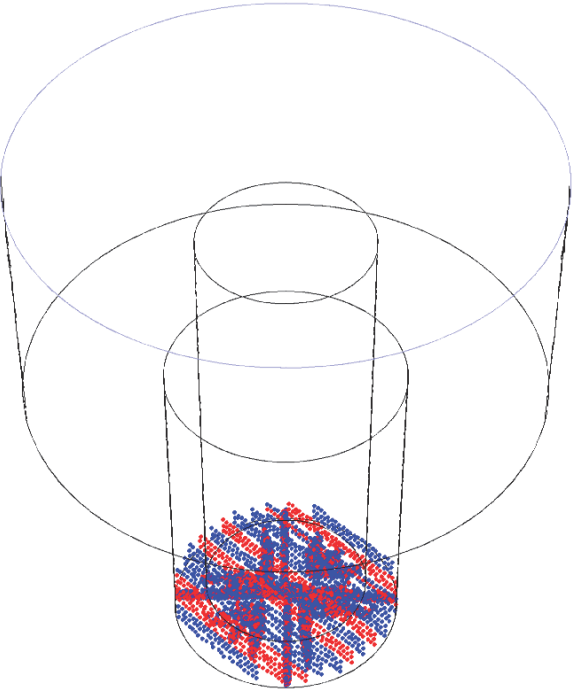

(b) After one period

FIgURE 5: Gap flow field with $2 \mathrm{~mm}$ deep hole.

TABLE 1: Continuous discharge simulating parameters.

\begin{tabular}{lc}
\hline Parameter & Description \\
\hline Dielectric fluid & Deionized water \\
Tool & Copper \\
Workpiece & TC4 \\
Tool velocity & $0.01 \mathrm{~m} / \mathrm{s}$ \\
Polarity & Positive \\
Diameter $(\mathrm{mm})$ & 1,2 \\
Flushing vel. $(\mathrm{m} / \mathrm{s})$ & $0,2,5$ \\
Depth $(\mathrm{mm})$ & $0.5,2.0,3.5,5.0$ \\
\hline
\end{tabular}

tool diameter are shown in Figures 4 and 5. Figures 4 and 5 show the gap flow field with $0.5 \mathrm{~mm}$ and $2.0 \mathrm{~mm}$ deep hole, respectively. In Figures 4 and 5, the tool initially moves down from the top to the bottom and finally returns to the original position. During the tool moving down process, a positive pressure is formed at the bottom, which drives the dielectric and debris at the bottom to the surrounding region, as shown in Figures 4(a) and 5(a). But no debris is carried out from bottom because the fluid velocity is low. In the next half period, the tool begins to move up, which results in the negative pressure at bottom. The negative pressure causes the fresh dielectric drawn into the gap, which pushes the debris to the center, as shown in Figures 4(b) and 5(b). From Figures 4 and 5, no debris is removed out of machining region. One conclusion could be drawn that, without flushing, the depth of the small hole has little influence on the debris distribution. It should be noticed that the accumulative debris stayed at the bottom increase the probability of concentrated discharges, which could generate the burn marks. 


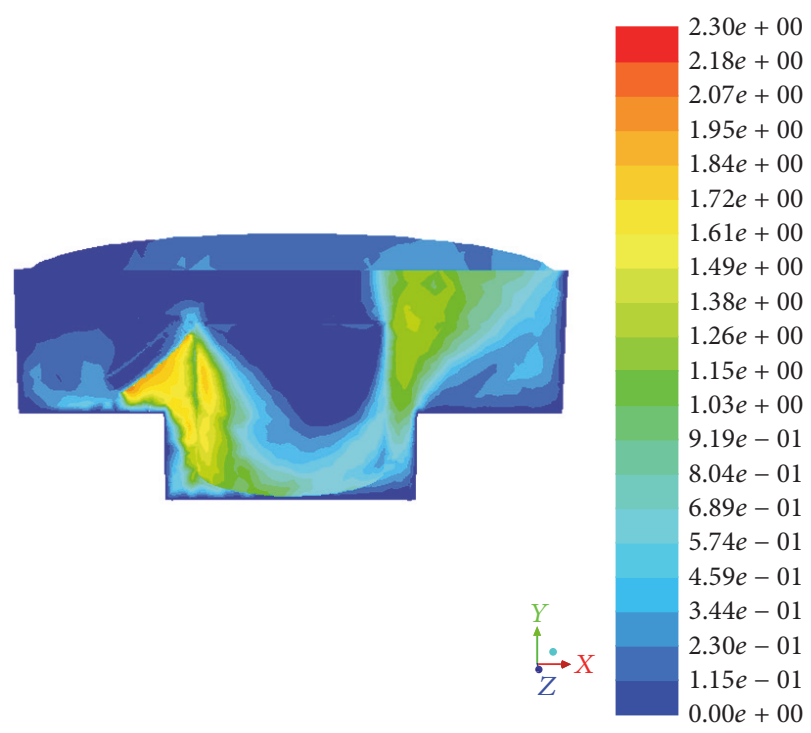

(a) Velocity field

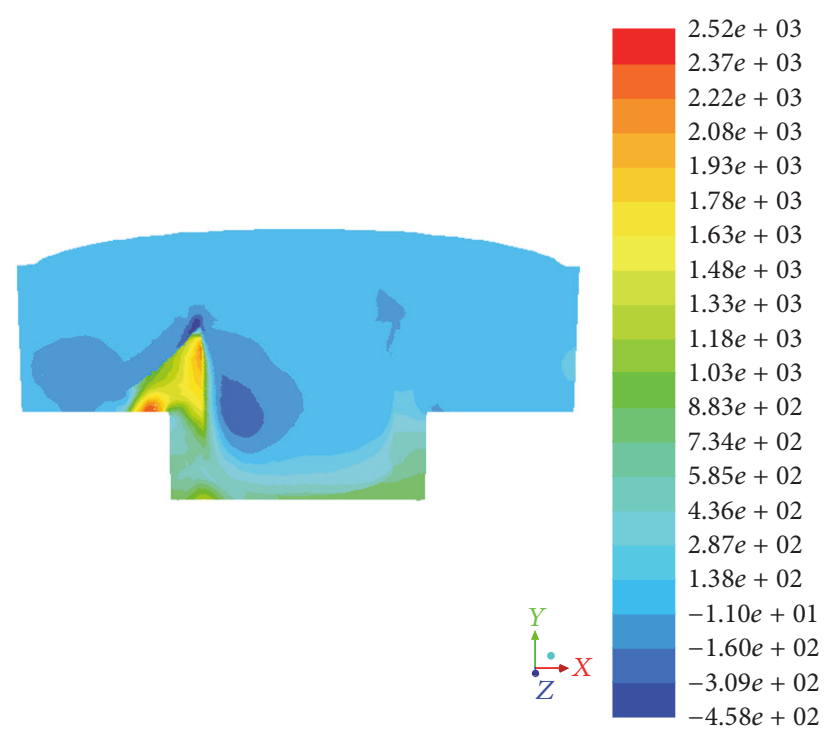

(b) Pressure field

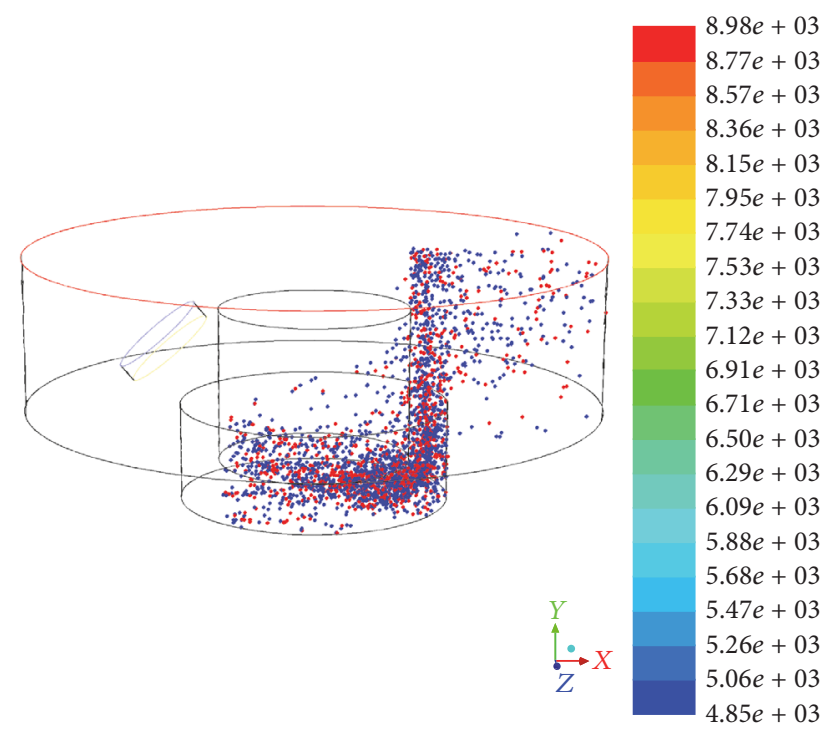

(c) Debris distribution

FIGURE 6: Schematics of gap flow field with flushing at $2 \mathrm{~m} / \mathrm{s}$ and $0.5 \mathrm{~mm}$ deep hole.

4.2. Impact Analysis of Gap Flow Field with $1 \mathrm{~mm}$ Tool Diameter. In ordinary EDM machining, the flushing is introduced to bring fresh dielectric fluid into the gap and lower the debris concentration. In order to conduct the impact of flushing on the debris distribution, the flushing is applied in simulation model. In the model with flushing, a dielectric tube aimed at the gap between tool and workpiece induces the flow through the machining gap. Figures 6-13 show the simulation results in the case of $1 \mathrm{~mm}$ tool diameter after one period.

Figure 6 presents the gap flow field with flushing at $2 \mathrm{~m} / \mathrm{s}$ and $0.5 \mathrm{~mm}$ deep hole. As shown in Figure 6(a), the highest fluid velocity of $2.3 \mathrm{~m} / \mathrm{s}$ appears at the wall opposite to flushing direction. The fluid velocity at the bottom and right side gap is large. The fluid velocity of right side outlet is lower than that of left side inlet. The fluid velocity declines with the increase of hole depth. The highest pressure $2520 \mathrm{~Pa}$ appears at the inlet and the negative pressure zone also appears near the inlet, as shown in Figure 6(b). In Figure 6(c), the debris moves along the gap to the right side. Besides, a part of debris escapes from the machining areas due to the effect of flushing, as well as the hole with small depth. There is more debris left at the right corner than those at the left, which corresponds well with the velocity distribution in Figure 6(a).

Figure 7 presents the gap flow field with flushing at $5 \mathrm{~m} / \mathrm{s}$ and $0.5 \mathrm{~mm}$ deep hole. Compared with Figure 6, owing to the higher flushing velocity, the values of velocity field and 


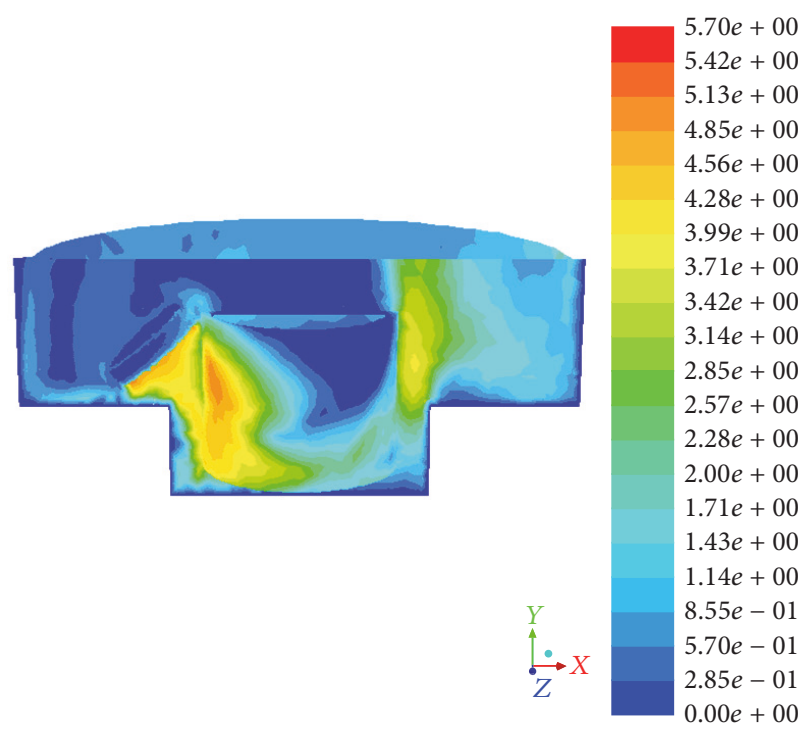

(a) Velocity field

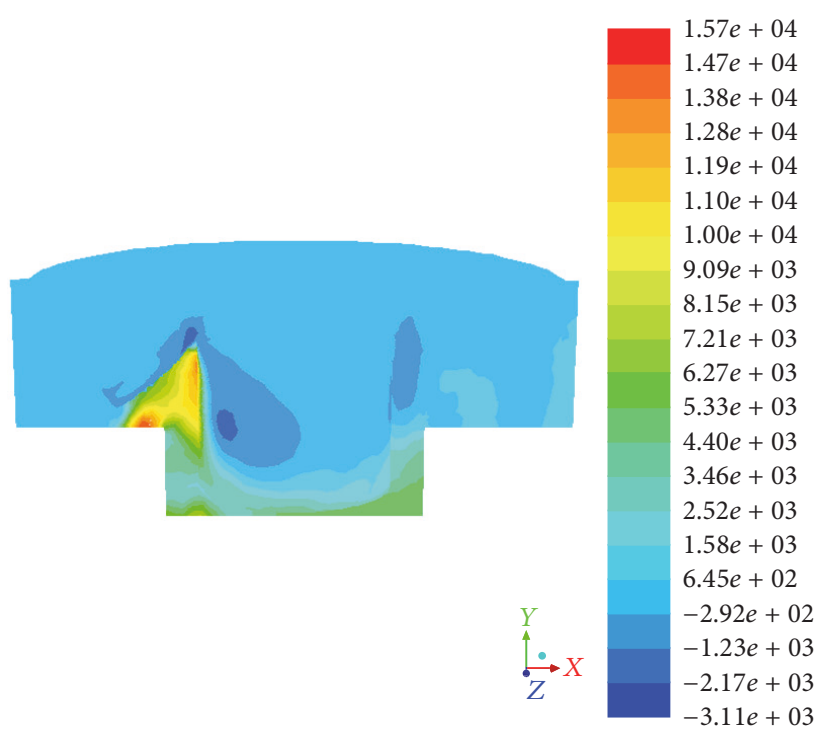

(b) Pressure field

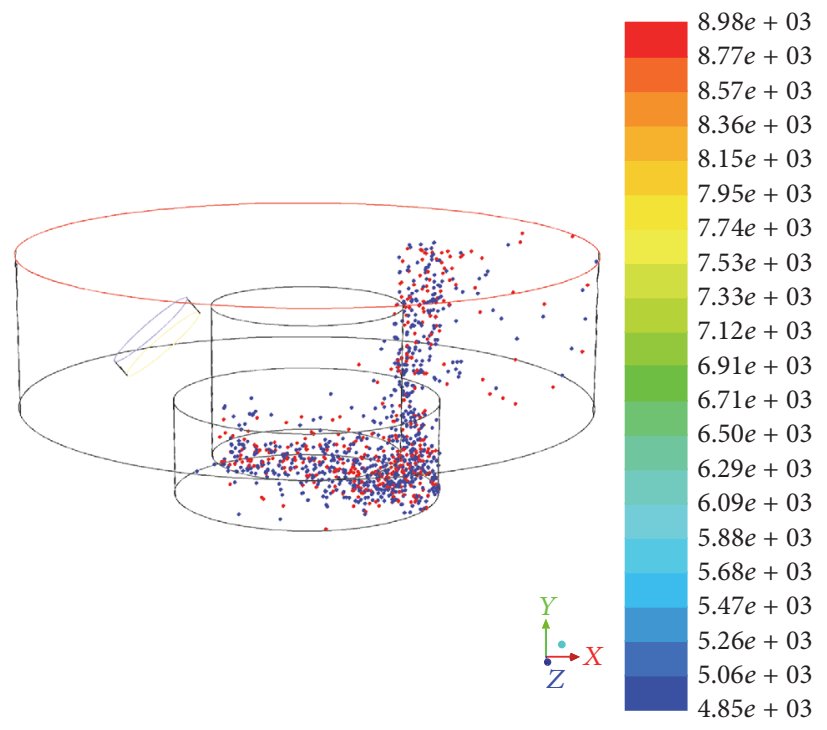

(c) Debris distribution

FIGURE 7: Schematics of gap flow field with flushing at $5 \mathrm{~m} / \mathrm{s}$ and $0.5 \mathrm{~mm}$ deep hole.

pressure field increase abruptly, and the highest fluid velocity and highest pressure reach $5.7 \mathrm{~m} / \mathrm{s}$ and $15700 \mathrm{~Pa}$, respectively. Compared with Figure 6, more debris is carried out of the hole, which results in the fact that less debris remains at the machining gap. The simulation results correspond well with the mathematical model. For Figures 6 and 7, a low fluid velocity zone appears at the lower right corner of tool. More debris accumulates at the low fluid velocity zone, which increases the probability of concentrated discharges and blunts the edge of tool.

Figure 8 presents the gap flow field with flushing at $2 \mathrm{~m} / \mathrm{s}$ and $2.0 \mathrm{~mm}$ deep hole. Compared with Figure 6, the flushing effect at bottom of hole becomes poor, which results in the poor debris removal at bottom. Only tiny of debris is flushed away, as shown in Figure 8(c). More debris is accumulated at the right corner of bottom.

Figure 9 presents the gap flow field with flushing at $5 \mathrm{~m} / \mathrm{s}$ and $2.0 \mathrm{~mm}$ deep hole. With high velocity, more fluid is injected into the deep gap, even at the bottom gap. So compared with Figure 7, more debris is carried away by the fluid. But compared with Figure 7, as the hole becomes deeper, there are more debris left at the bottom. The simulation results correspond well with the mathematical model. In Figures 8 and 9, a lot of debris accumulates at the right side gap, which 


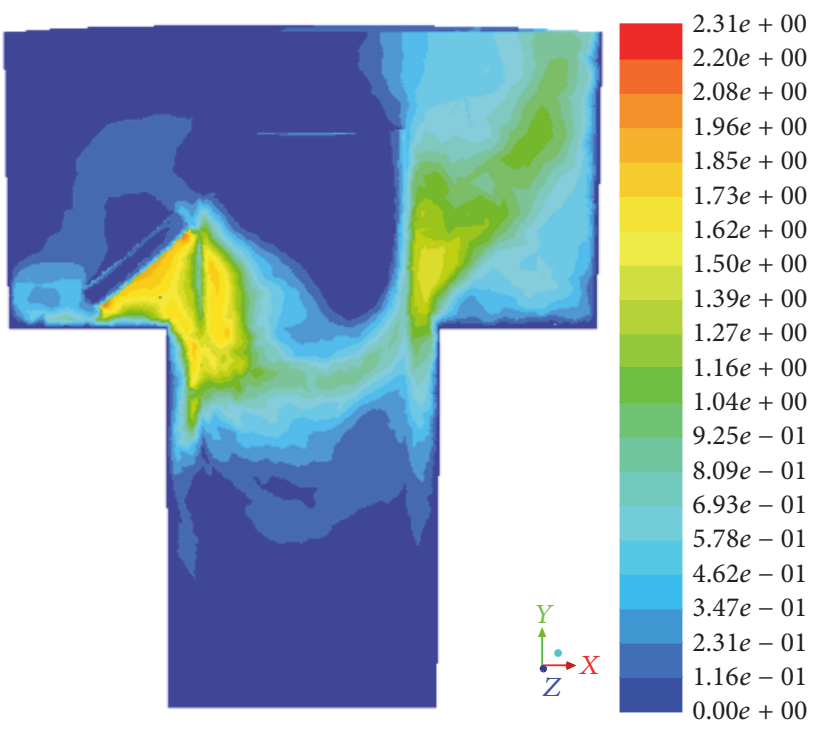

(a) Velocity field

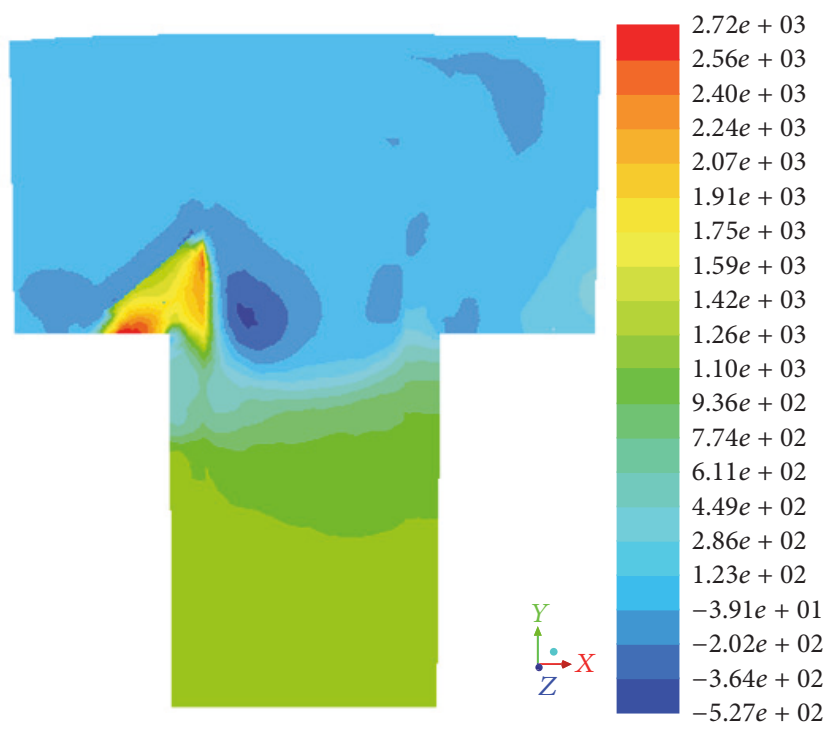

(b) Pressure field

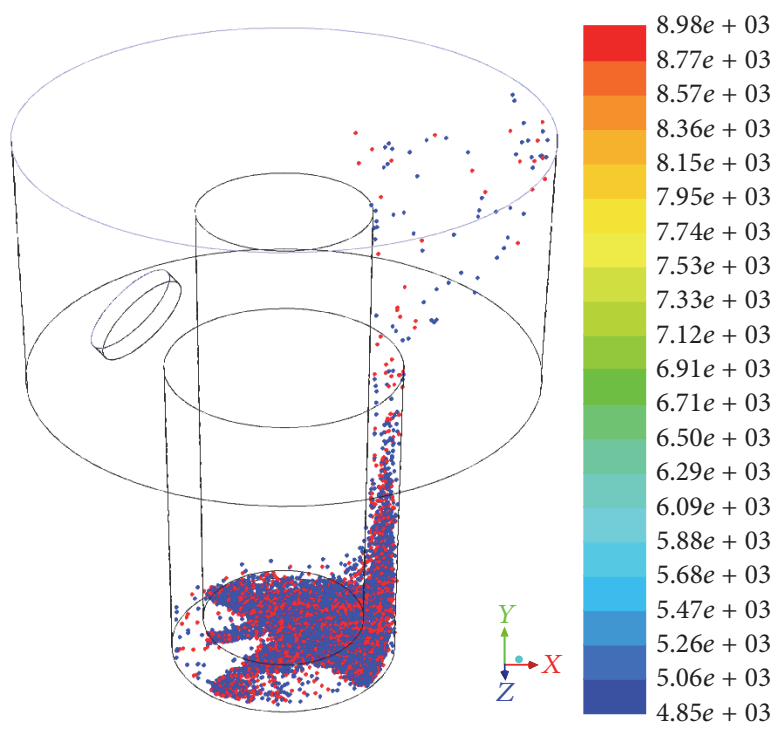

(c) Debris distribution

FIgURE 8: Schematics of gap flow field with flushing at $2 \mathrm{~m} / \mathrm{s}$ and $2 \mathrm{~mm}$ deep hole.

increases the probability of secondary discharges between the sides of tool and right wall of hole and then increases the inclination of right wall of hole.

As shown from Figures 10 and 11, $3.5 \mathrm{~mm}$ deep hole is considered with different flushing velocity. From the simulation results, no flushing fluid is injected into the bottom gap of hole with depth over $3.5 \mathrm{~mm}$. The pressure decreases sharply at the bottom, where the velocity is close to zero and the fluid velocity in this region is concerned with the tool movement. As the disturbance induced by the tool movement is small, all the debris stays at the bottom. In the case of $5 \mathrm{~mm}$ deep hole a similar result is obtained.
Compared with Figures 6-9, a conclusion can be made that when the depth to diameter ratio exceeds 3 , no debris could be removed from the gap. The debris accumulates at the bottom and may create concentrated discharges between the workpiece and tool.

4.3. Impact of Tool Movement on Gap Flow Field with $2 \mathrm{~mm}$ Tool Diameter. Figures 12-19 are the simulation results in the case of $2 \mathrm{~mm}$ tool diameter. Figure 12 shows the gap flow field with flushing at $2 \mathrm{~m} / \mathrm{s}$ and $0.5 \mathrm{~mm}$ deep hole. The highest velocity $2.75 \mathrm{~m} / \mathrm{s}$ appears at the wall opposite to flushing direction, where a low pressure zone forms. The debris is 


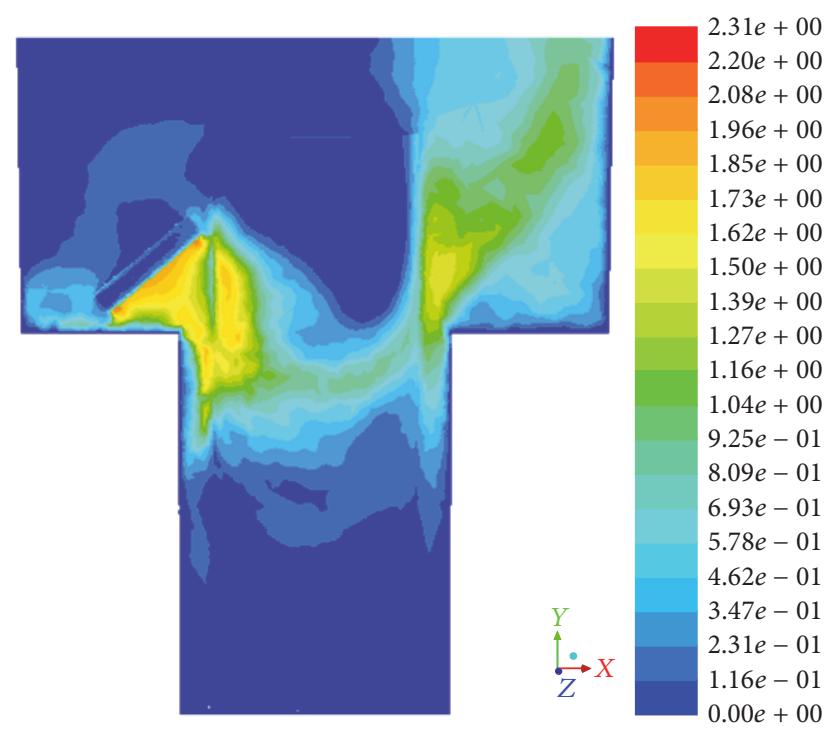

(a) Velocity field

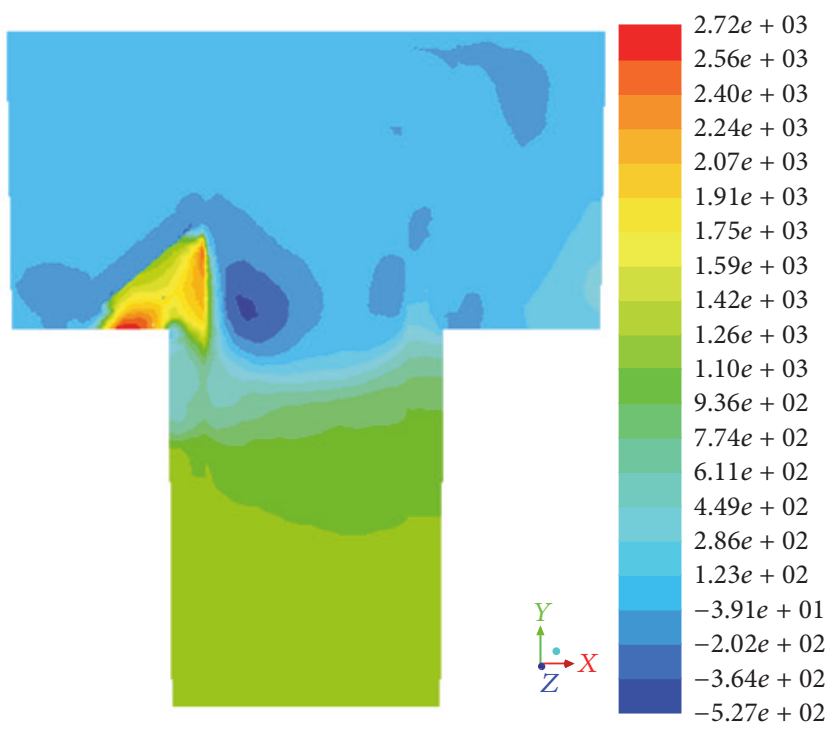

(b) Pressure field

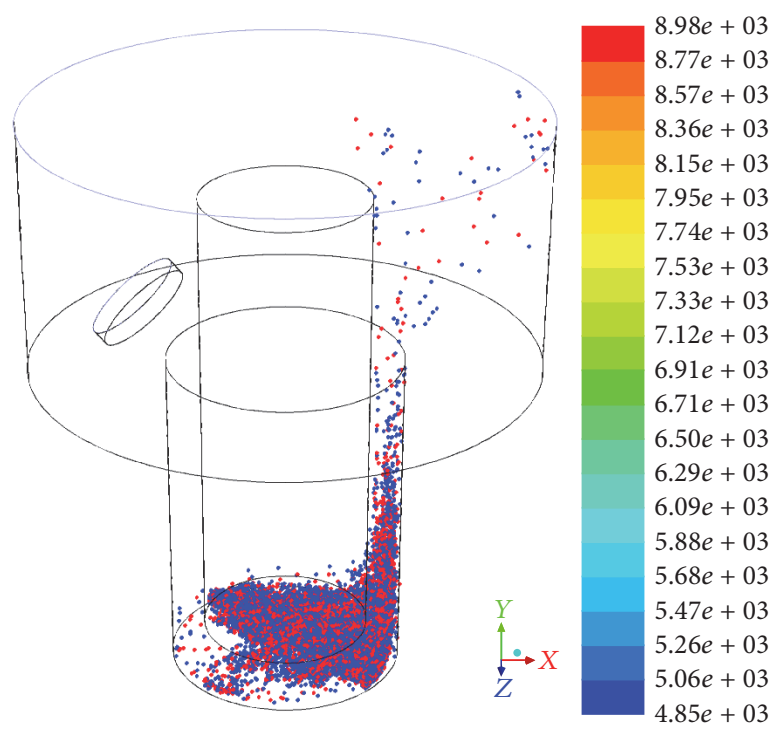

(c) Debris distribution

FIgURE 9: Schematics of gap flow field with flushing at $5 \mathrm{~m} / \mathrm{s}$ and $2 \mathrm{~mm}$ deep hole.

flushed to the right corner of bottom, and the debris is flushed out from the right gap to unmachined area. Compared with Figure 6, both velocity and pressure are much higher and more debris is carried away. In case of Figure 12 the tool diameter is twice of that in Figure 6, which increases the curvature radius of gap. So the flushing fluid suffers the less resistance during the flowing, which is positive for the debris to be flushed out. However, with the increase of tool diameter, the diameter of the bottom gap increases. Large bottom gap increases the debris removal distance, which is negative for the debris to be flushed out.

Figure 13 shows the gap flow field with fluid flushing at $5 \mathrm{~m} / \mathrm{s}$ and $0.5 \mathrm{~mm}$ deep hole. In Figure 13(a), the largest velocity reaches $6.67 \mathrm{~m} / \mathrm{s}$ and the highest pressure increases to $22800 \mathrm{~Pa}$. There is sufficient pressure for the flushing injecting into the gap and driving more debris to the right side gap. Compared with Figure 12, less debris remains at the machined area.

Figures 14 and 15 are the gap flow fields of different flushing velocity with $2 \mathrm{~mm}$ deep hole. Compared with Figures 8 and 9 , under the same machining condition, the fluid velocity at the bottom becomes larger in the case of a large tool diameter. More debris is flushed away and less debris remains at the bottom. Besides, in Figures 14 and 15, the debris is flushed out approximately in a line from the right gap and then dispersed near workpiece surface. It is confirmed 


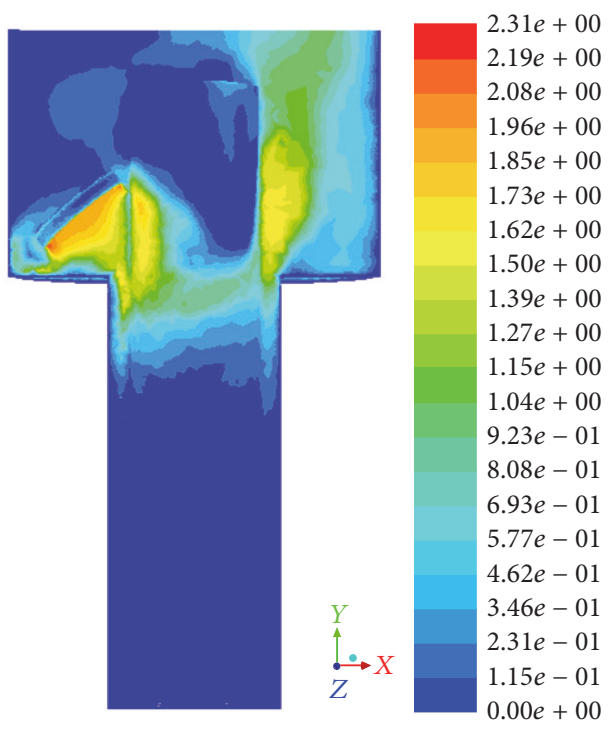

(a) Velocity field

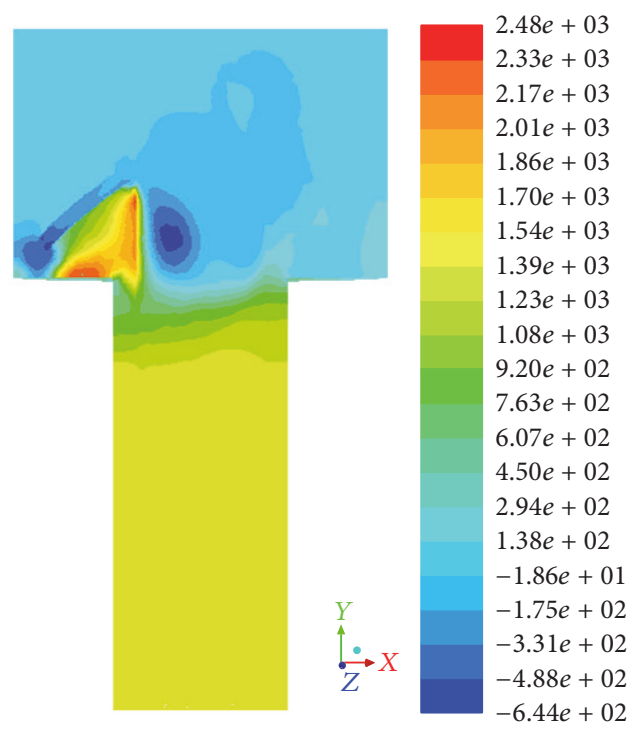

(b) Pressure field

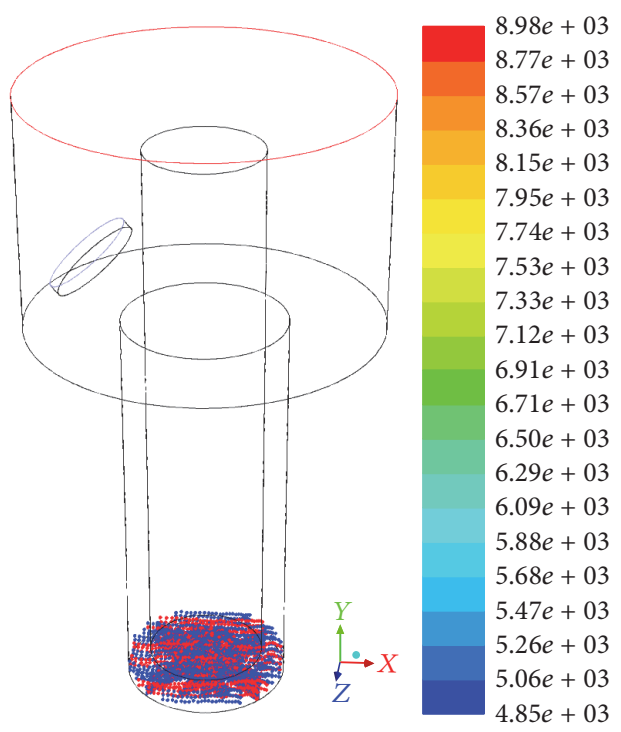

(c) Debris distribution

FIGURE 10: Schematics of gap flow field with flushing at $2 \mathrm{~m} / \mathrm{s}$ and $3.5 \mathrm{~mm}$ deep hole.

that the fluid velocity at the bottom is low and a larger velocity appears in the rightmost gap, which corresponds well with the velocity field. When the fluid reaches the outlet, the velocity suddenly increases, which results in the dispersion of debris. A lot of debris accumulates at the right side gap, which increases the probability of secondary discharges between the tool and right wall of hole and then increases the inclination of right wall of hole. The low velocity region also appears at the right corner of bottom gap. The debris easily stays at the low velocity region, which could cause discharge between debris and workpiece. Then the burn mark could happen in practical operation.
Comparing $3.5 \mathrm{~mm}$ deep hole with $5 \mathrm{~mm}$, as shown in Figures 16-19, the flushing liquid is injected into the gap and there is sufficient pressure to remove the debris. The debris can escape from $3.5 \mathrm{~mm}$ deep hole. On the contrary, in case of $5 \mathrm{~mm}$ deep hole, the flushing liquid is hardly injected into the bottom gap. Besides, the bottom velocity is only concerned with the tool movement and no debris could be flushed out from $5 \mathrm{~mm}$ deep hole. In this situation, the discharge stability decreases.

Combining the above analysis, one conclusion could be drawn that, for the $2 \mathrm{~mm}$ tool diameter, the flushing fluid contains less resistance than those of $1 \mathrm{~mm}$ tool diameter, 


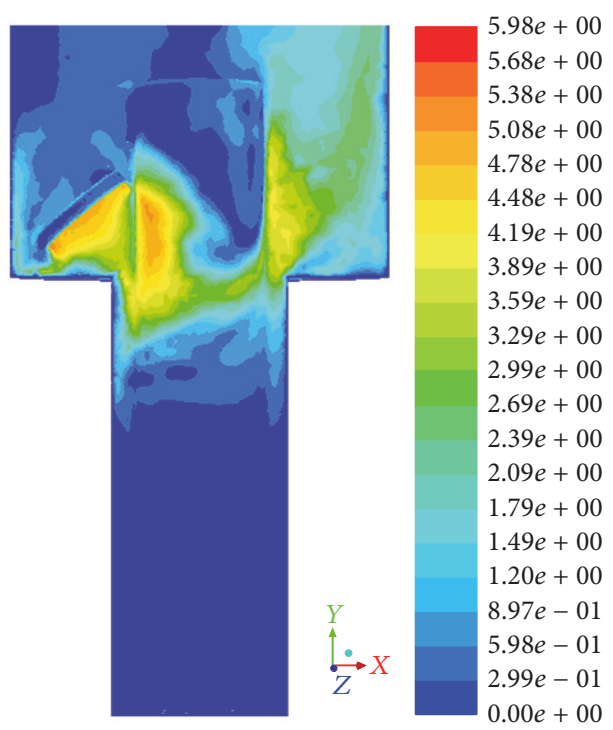

(a) Velocity field

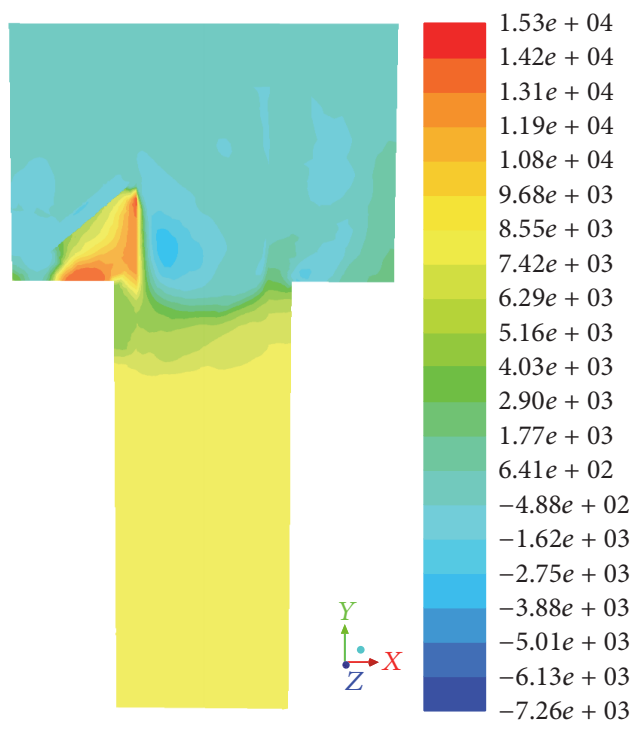

(b) Pressure field

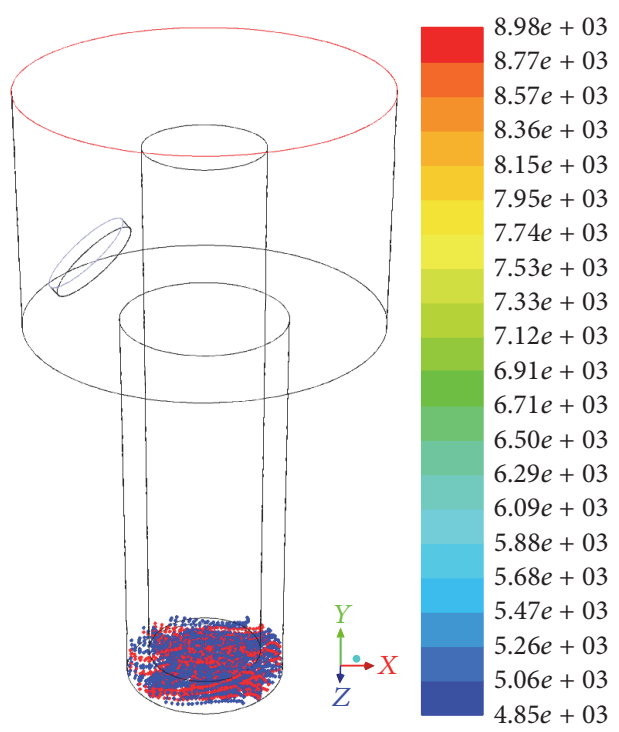

(c) Debris distribution

Figure 11: Schematics of gap flow field with flushing at $5 \mathrm{~m} / \mathrm{s}$ and $3.5 \mathrm{~mm}$ deep hole.

which results in the fluid with higher velocity. Finally, more debris is taken away by the flushing fluid. On the contrary, in situation with lower fluid velocity, the flushing fluid with insufficient drag force could hardly bring the debris out of bottom gap. Such phenomenon could be deduced for deep hole with micro- or smaller diameter.

\section{Impact of Machining Parameters on Debris Distribution}

In order to obtain the debris distribution in machining region, the coordinate of each debris is exported for statistics. For the convenience of analysis, the machining region is divided into 5 zones, as shown in Figure 20(a). Zone S1 is the left bottom gap, zone S2 is the right bottom gap, zone S3 is the left side gap, zone S4 is the right side gap, and S5 is the dielectric zone above the workpiece. Figure 20(b) shows the bird view of the machining zone. In the following section, the debris distributions under different parameters are analyzed.

5.1. Impact of Hole Depths on the Debris Distribution. Figure 21 presents the debris distribution with different hole depths. As shown in Figure 21(a), for the depth of $0.5 \mathrm{~mm}$, S1-S5 contain the debris in $1.1 \%, 15.4 \%, 0.0 \%, 3.4 \%$, and $80.1 \%$. The final inequation for the debris concentration is S5 $>$ S2 $>$ S4 $>$ S1 $>$ S3. Most debris gets out from the machining zone. 


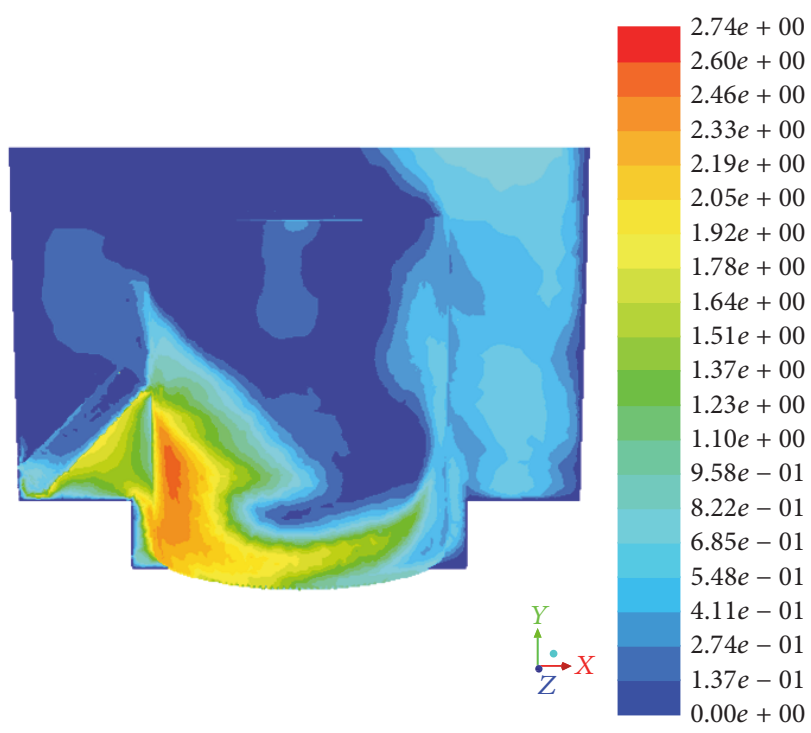

(a) Velocity field

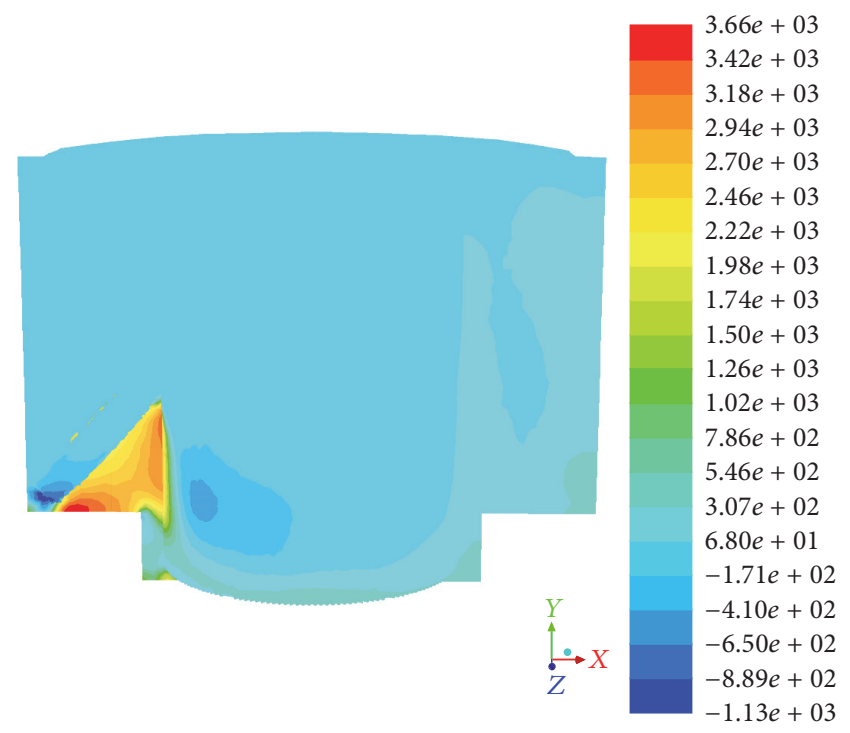

(b) Pressure field

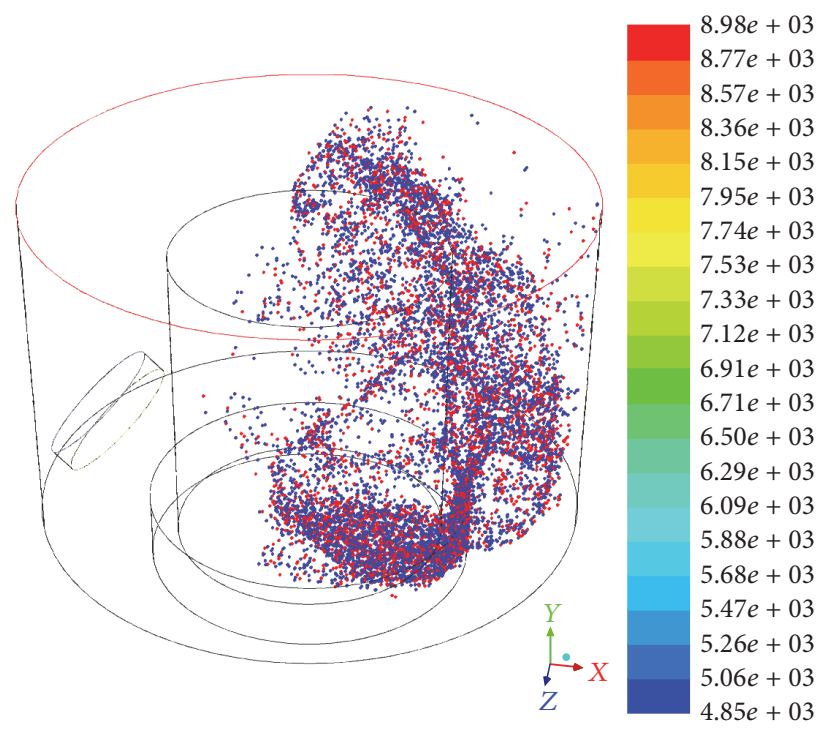

(c) Debris distribution

Figure 12: Schematics of gap flow field with flushing at $2 \mathrm{~m} / \mathrm{s}$ and $0.5 \mathrm{~mm}$ deep hole.

For the debris remaining at machining zone, major part of debris is distributed at the right bottom gap (zone S2). For the $0.5 \mathrm{~mm}$ deep hole, the sufficient pressure at bottom gap could flush most debris out of hole. The debris distribution of hole with $2.0 \mathrm{~mm}$ deep hole is similar to that of $0.5 \mathrm{~mm}$ deep hole. In case of the $3.5 \mathrm{~mm}$ deep hole, most debris stays in zone S2 (65.3\%); secondly in zone S1 (17.9\%), only a little debris is distributed in zone S5 (4.8\%); that is to say, a little debris is removed from the gap; a little debris is in the process of escaping (S4 (12.1\%)). Most debris stays at the bottom (zones S1 and S2) and right side gap (zone S4) of the machining area. The reason of this is that as the hole is deep, the flush of tube has a little impact on the gap near the bottom, and a little dielectric is injected into this region. Compared with $0.5 \mathrm{~mm}$ and $2 \mathrm{~mm}$ deep hole, only a little debris is carried away. However, in the case of $5 \mathrm{~mm}$ deep hole, almost no debris is carried away from the hole.

With the constant of tool diameter and fluid velocity in $5 \mathrm{~m} / \mathrm{s}$, the debris distribution is similar to that of fluid velocity in $2 \mathrm{~m} / \mathrm{s}$, except the debris distribution in S4 zone, just as shown in Figure 21(b). In the shallow hole $(0.5 \mathrm{~mm}$, $2 \mathrm{~mm}$ ) machining, there is more debris in the condition of lower velocity than that of higher velocity, while, in the deep hole $(3.5 \mathrm{~mm}, 5 \mathrm{~mm})$ machining, there is less debris in the 


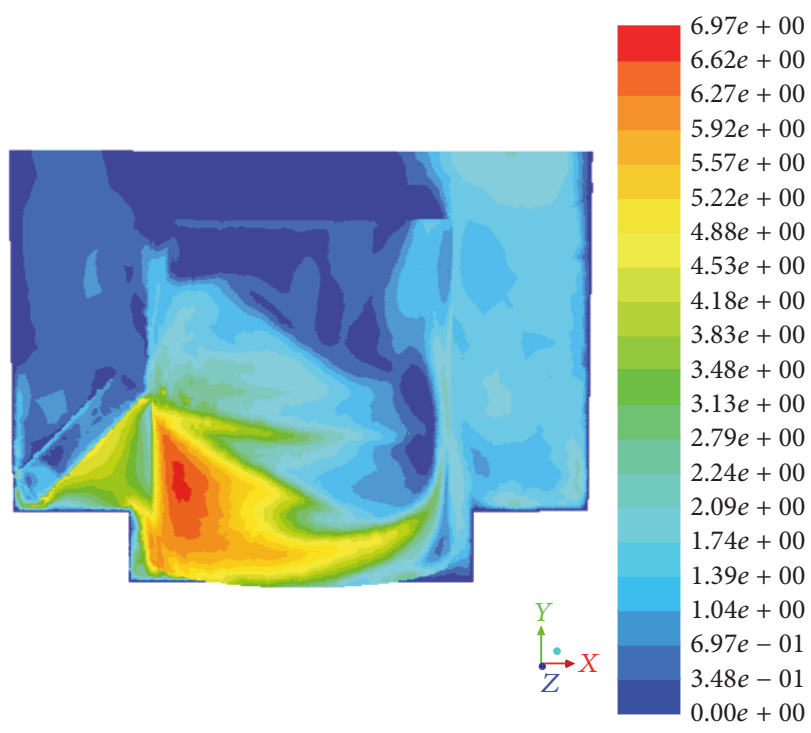

(a) Velocity field

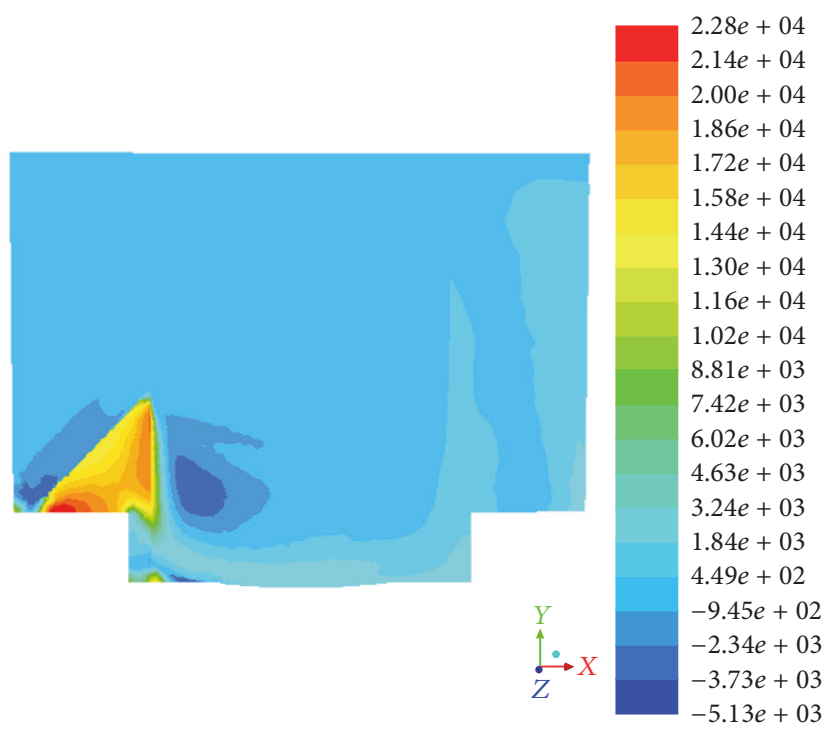

(b) Pressure field

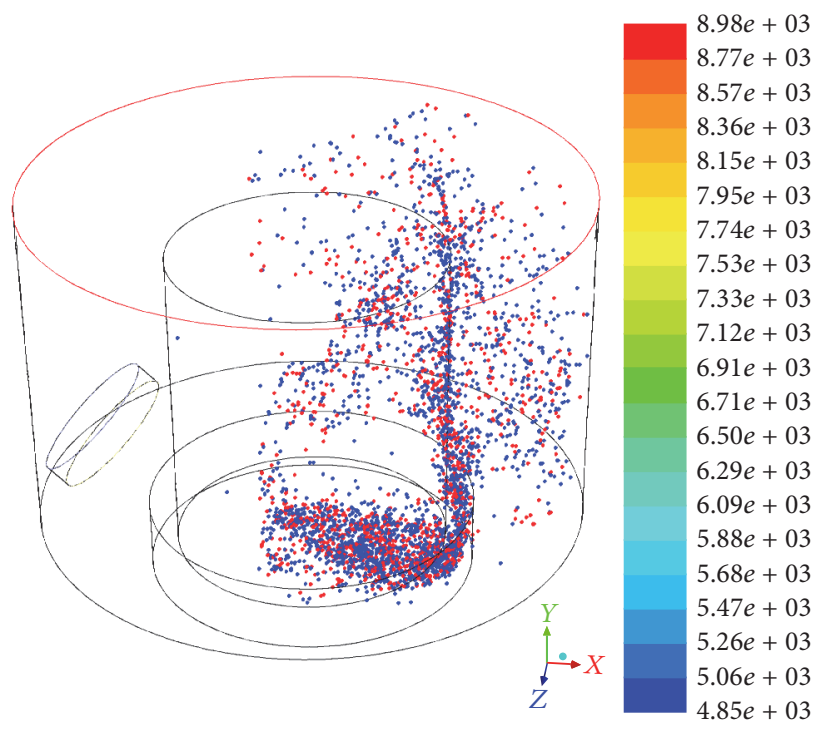

(c) Debris distribution

FIGURE 13: Schematics of gap flow field with flushing at $5 \mathrm{~m} / \mathrm{s}$ and $0.5 \mathrm{~mm}$ deep hole.

condition of lower velocity than that of higher velocity. The reason is that, in a shallower hole, debris flushed from S4 to S5 is less than that from S2 to S4; thus, S4 has more debris, while, in a deeper hole, the situation is on the contrary. Comparing Figure 21(a) with Figure 21(b), a conclusion can be made that, with a high velocity and a shallow hole, it is much easier for the debris to be washed away.

5.2. Impact of Tool Diameters on the Debris Distribution. Figure 22 presents the impact of different tool diameters on the debris distribution with flushing velocity at $5 \mathrm{~m} / \mathrm{s}$.
As shown in Figure 22(a), there is more debris in zones S1 (23.1\%) and S2 (60.4\%) than other zones in the case of $1 \mathrm{~mm}$ tool diameter; however most debris is swept to S5 (9.3\%) in the case of $2 \mathrm{~mm}$ tool diameter. A large diameter is more beneficial than small diameter for removing debris. It is because, with a large diameter, the curvature radius is large, the flushing can directly get into the gap with less resistance, and the debris is easily washed away. However, with a small diameter, the curvature radius is smaller, the flushing flows against the wall, the velocity declines sharply, and there is insufficient pressure to take away the debris. As a result, the debris could hardly be removed from the gap. 


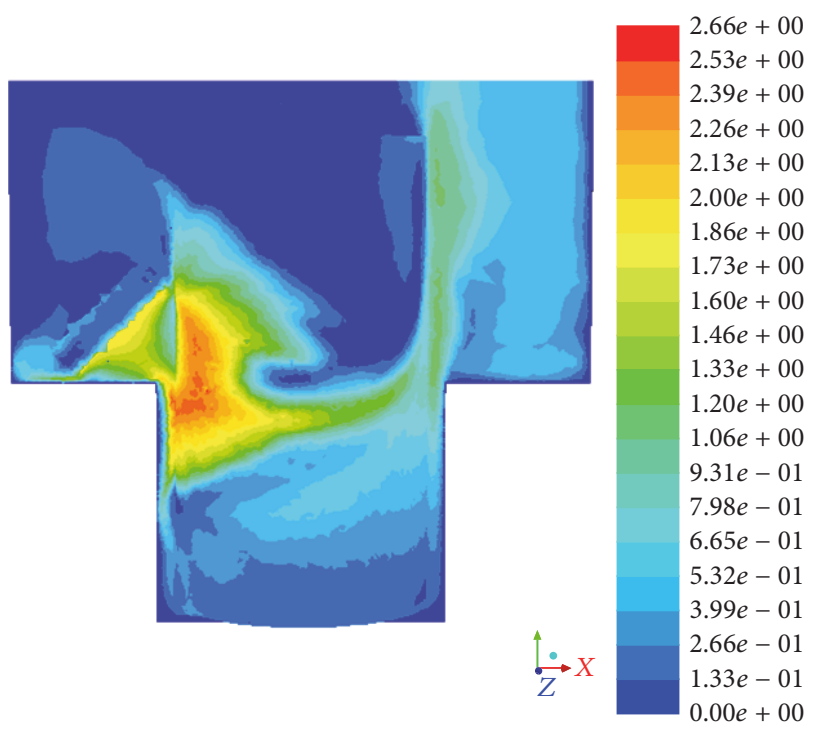

(a) Velocity field

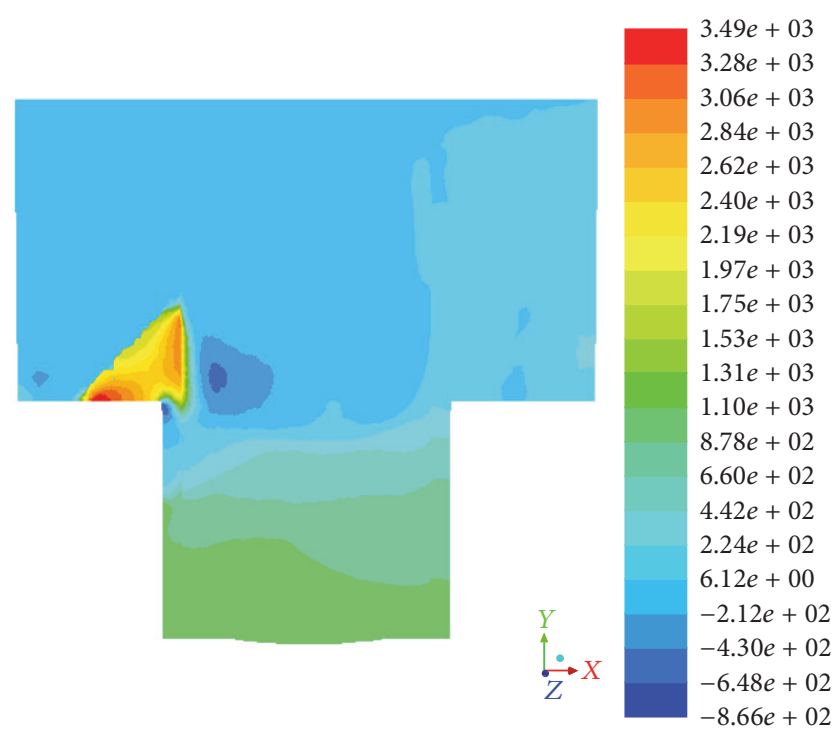

(b) Pressure field

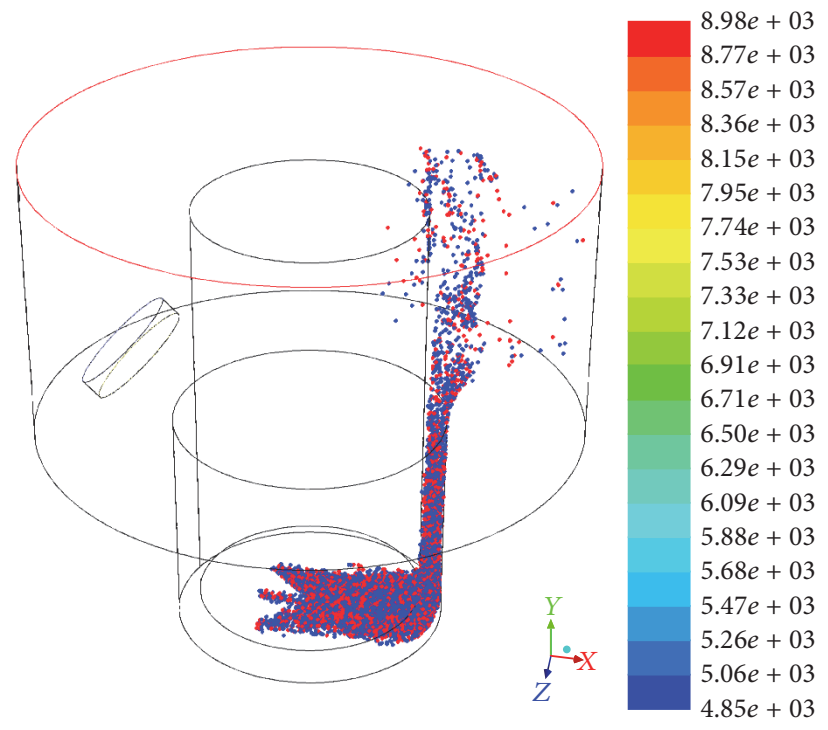

(c) Debris distribution

FIGURE 14: Schematics of gap flow field with flushing at $2 \mathrm{~m} / \mathrm{s}$ and $2 \mathrm{~mm}$ deep hole.

Figure 22(b) presents a statistical result in a deeper hole. As shown in Figure 22(b), most debris stays in S1 (50.9\%) and S2 (49.1\%); almost no debris is carried away, as there is no enough pressure for the dielectric flowing into the gap; debris stays at the bottom. In the case of $1 \mathrm{~mm}$ tool diameter, the debris distributed in S1 and S2 is almost the same; however, in the case of $2 \mathrm{~mm}$ tool diameter, there is more debris in S2 than S1, which indicates that some debris in the left bottom gap is washed to the right. The impact of tool diameters on the debris distribution is proven again.
Comparing Figure 22(a) with Figure 22(b), in the case of $1 \mathrm{~mm}$ tool diameter, zone S1 has less debris than zone S2 (see Figure 22(a)), whereas for the deeper hole (see Figure 22(b)), the quantity of debris in zones S1 and S2 is similar. In the case of $2 \mathrm{~mm}$ tool diameter, most debris is swept away from the hole (see Figure 22(a)), whereas for a deeper hole, the diameter is of limited effect on the debris distribution.

A conclusion can also be made that, in the case of a shallow hole, a larger diameter is conducive to remove more debris, whereas in a deeper hole, the tool diameter has little 


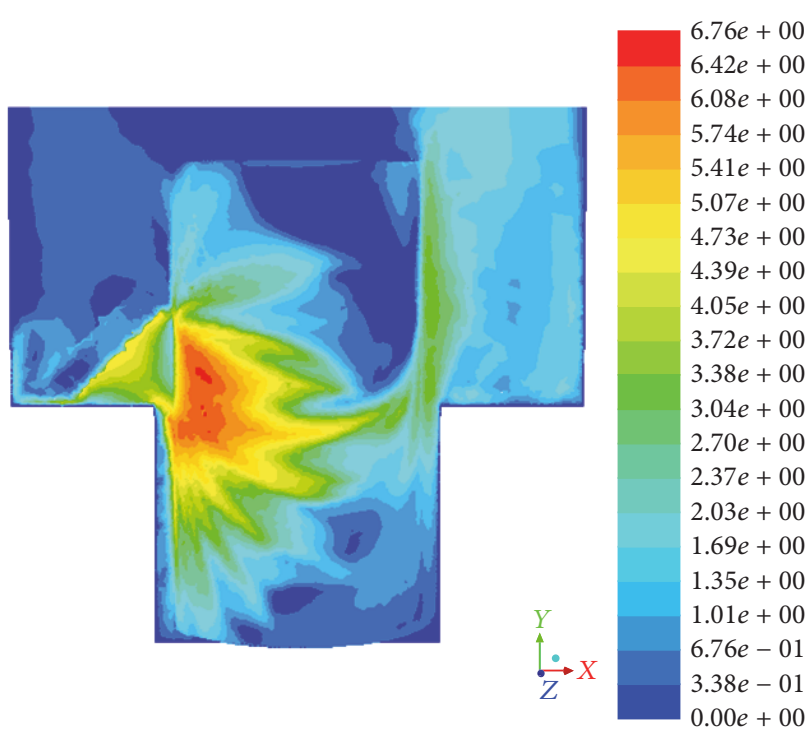

(a) Velocity field

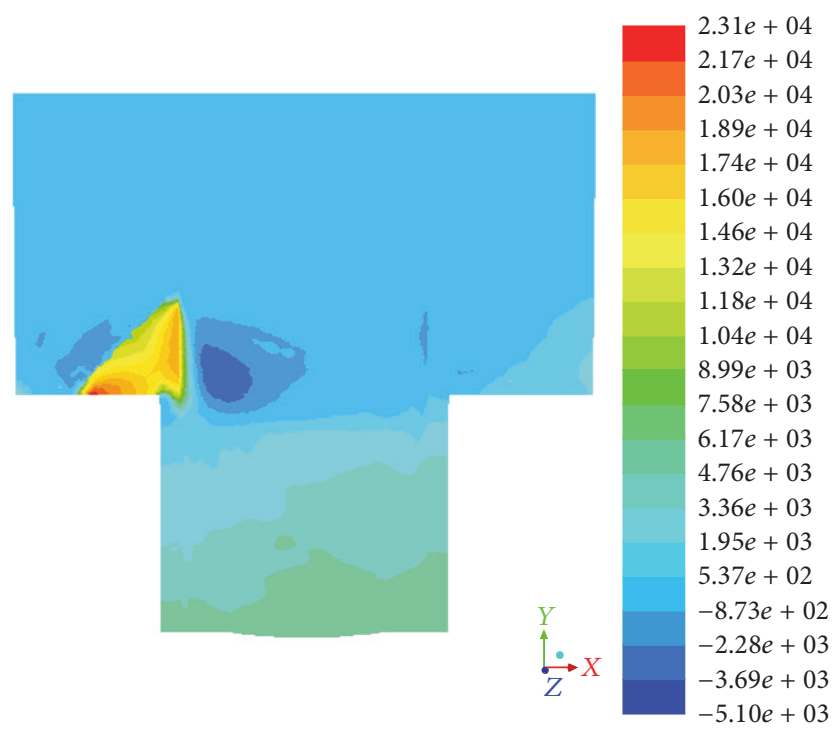

(b) Pressure field

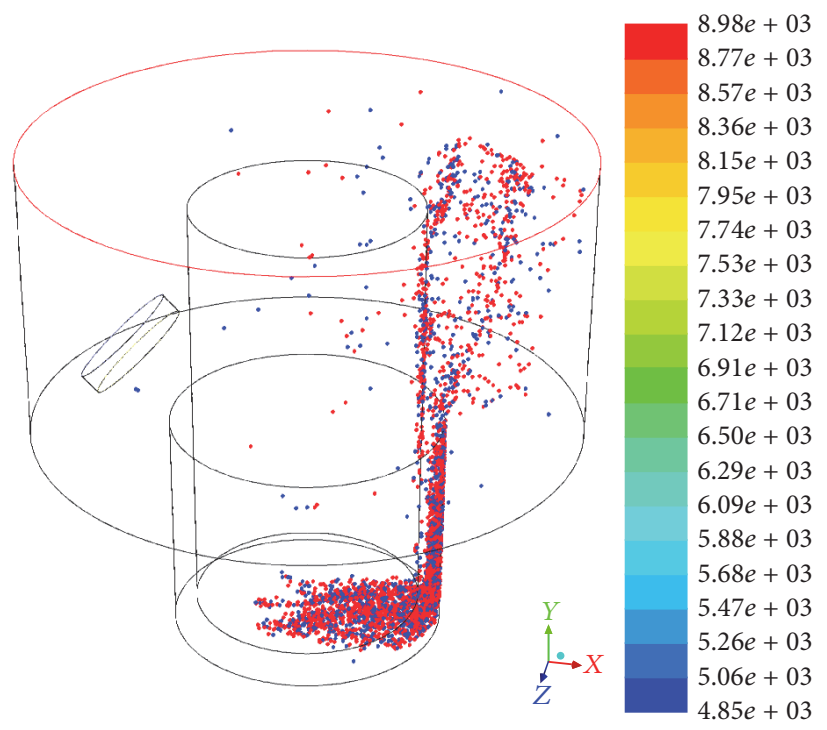

(c) Debris distribution

FIGURE 15: Schematics of gap flow field with flushing at $5 \mathrm{~m} / \mathrm{s}$ and $2 \mathrm{~mm}$ deep hole.

impact on the debris distribution, and debris can hardly be removed.

\subsection{Impact Analysis of Different Material Debris Distribution.} Figure 23 illustrates the impact of flushing velocities and tool diameters on two kinds of debris distributions. As shown in Figure 23(a), from the view of debris distribution of every zone, the distribution rate of each zone for $\mathrm{Ti}$ to $\mathrm{Cu}$ is basically the same; Ti debris in each zone is approximately twice the quantity of $\mathrm{Cu}$ debris that is in accordance with settings. The quantity of removed $\mathrm{Cu}$ debris is a little less than that of half of the $\mathrm{Ti}$ debris and the remaining $\mathrm{Cu}$ debris is a little larger than that of half of the Ti debris. For instance, in the case of $0.5 \mathrm{~mm}$ deep hole, $2 \mathrm{~mm}$ tool diameter, and $2 \mathrm{~m} / \mathrm{s}$ flushing, the quantity percentage of $\mathrm{Cu}$ debris in $\mathrm{S} 4$ and S5 is $81.5 \%$ (S4 (2.5\%); S5 (79.0\%)), the quantity percentage of Ti debris in S4 and S5 is $84.0 \%$ (S4 (2.3\%); S5 (81.7\%)), and the probable reason is that the density of $\mathrm{Cu}$ is larger than $\mathrm{Ti}$. In the case of $5 \mathrm{~m} / \mathrm{s}$, the removed percentage of $\mathrm{Cu}$ debris is $90.5 \%$ and $\mathrm{Ti}$ is $90.8 \%$, and the impact of debris material is of limit with high velocity. The velocity impact to $\mathrm{Cu}$ and $\mathrm{Ti}$ alloy debris distribution is of similar effects. Thus 


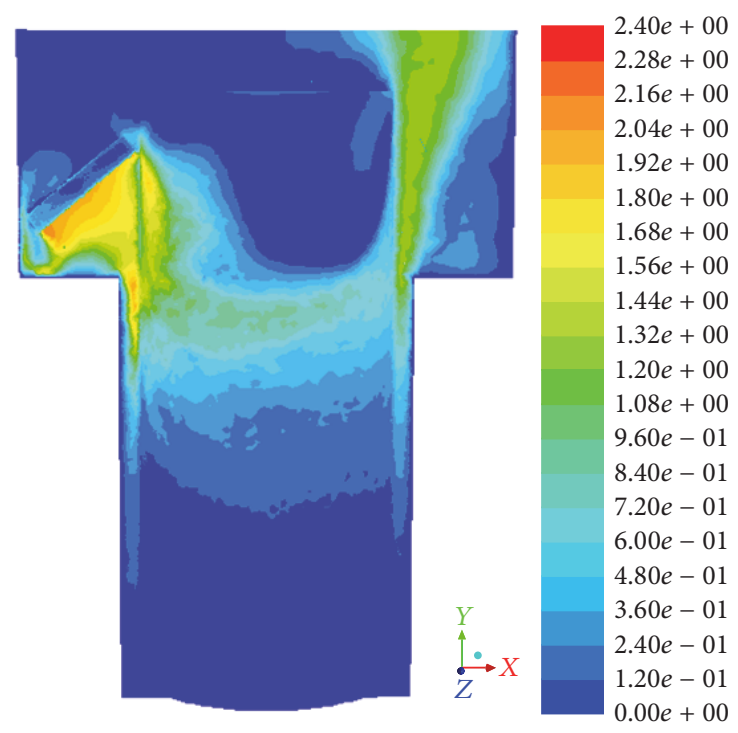

(a) Velocity field

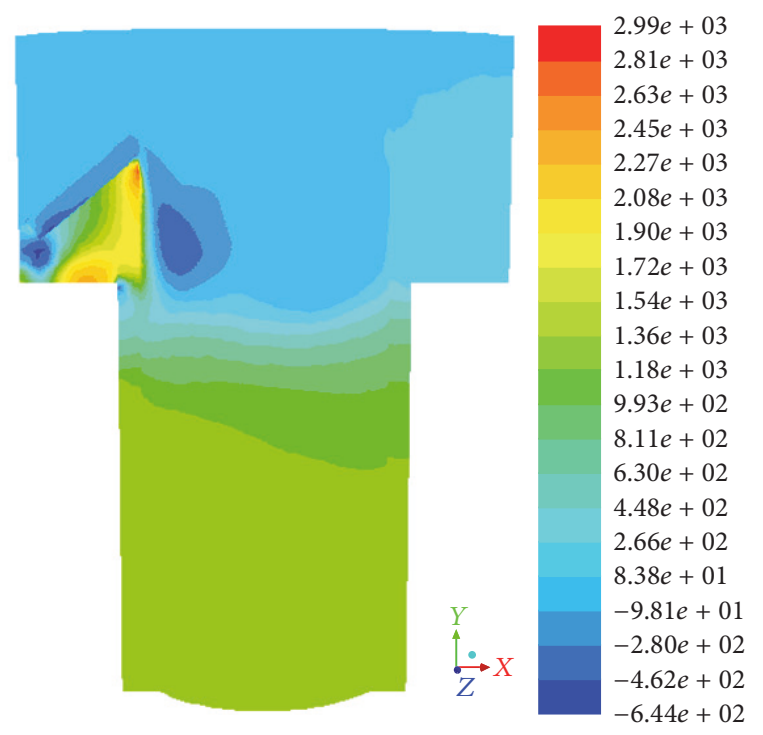

(b) Pressure field

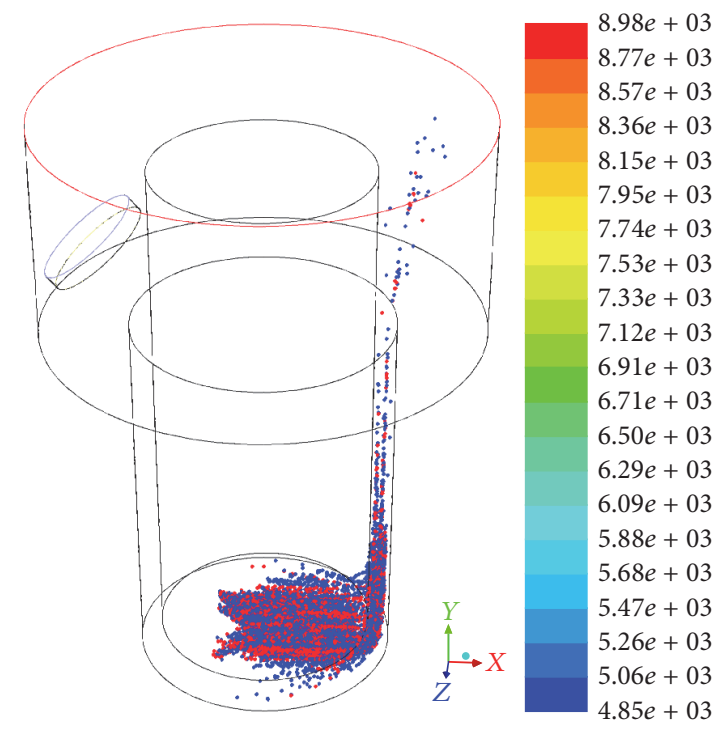

(c) Debris distribution

Figure 16: Schematics of gap flow field with flushing at $2 \mathrm{~m} / \mathrm{s}$ and $3.5 \mathrm{~mm}$ deep hole.

the velocity has a bit influence on the debris distribution of different materials.

Figure 23(b) presents the copper and Ti alloy distribution with different tool diameters. As shown in Figure 23(b), different material debris distribution between two different tool diameters is not so obvious. For instance, in the case of $3.5 \mathrm{~mm}$ deep hole, $1 \mathrm{~mm}$ tool diameter, and $2 \mathrm{~m} / \mathrm{s}$ flushing, the quantity percentage of $\mathrm{Cu}$ debris in $\mathrm{S} 1$ and $\mathrm{S} 2$ is $94.4 \%$ (S1 (44.6\%); S2 (49.8\%)) and the quantity percentage of Ti debris in S1 and S2 is $84.3 \%$ (S1 (44.2\%); S2 (40.1\%)). In the case of $3.5 \mathrm{~mm}$ deep hole, $2 \mathrm{~mm}$ tool diameter, and $2 \mathrm{~m} / \mathrm{s}$ flushing, the quantity percentage of $\mathrm{Cu}$ debris in $\mathrm{S} 1$ and $\mathrm{S} 2$ is $93.7 \%$ (S1 (18.7\%); S2 (75.0\%)) and the quantity percentage of Ti debris in S1 and S2 is $93.3 \%$ (S1 (18.2\%); S2 (75.1\%)). A conclusion can be made that, in the case of a large tool diameter, the quantity difference between $\mathrm{Ti}$ and $\mathrm{Cu}$ in $\mathrm{S} 1$ and $\mathrm{S} 2$ is around $10 \%$, whereas, in the case of a small tool diameter, the quantity difference between $\mathrm{Ti}$ and $\mathrm{Cu}$ in $\mathrm{S} 1$ and $\mathrm{S} 2$ is less than $1 \%$. The reason is that when the fluid flows through the gap with a large diameter, it suffers less resistance and has sufficient pressure to take away the debris from the gap. When the fluid flows through the gap with a small diameter, it suffers large 


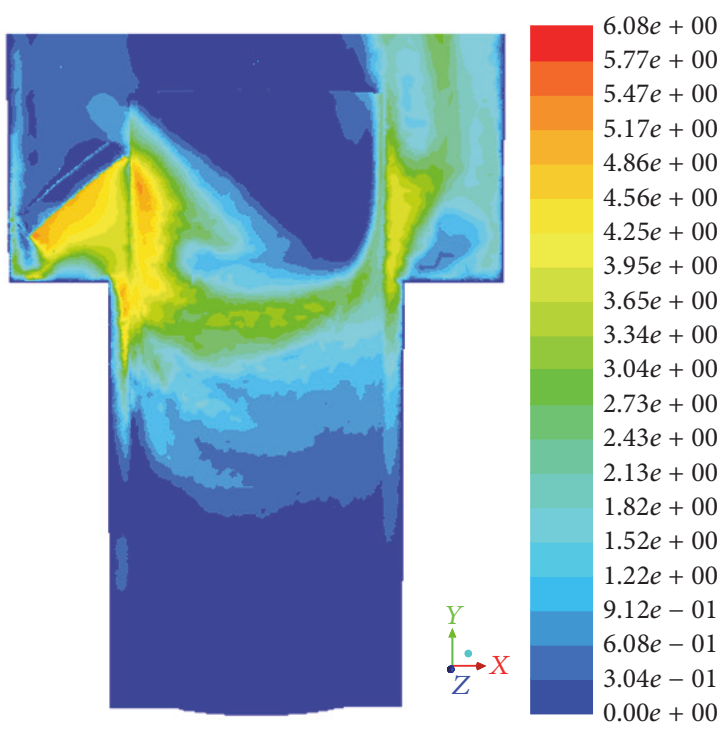

(a) Velocity field

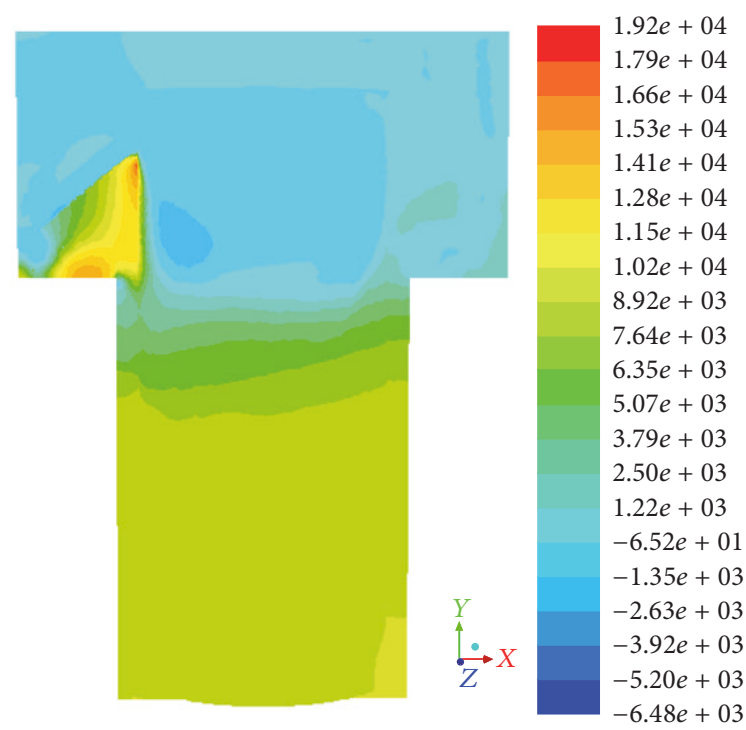

(b) Pressure field

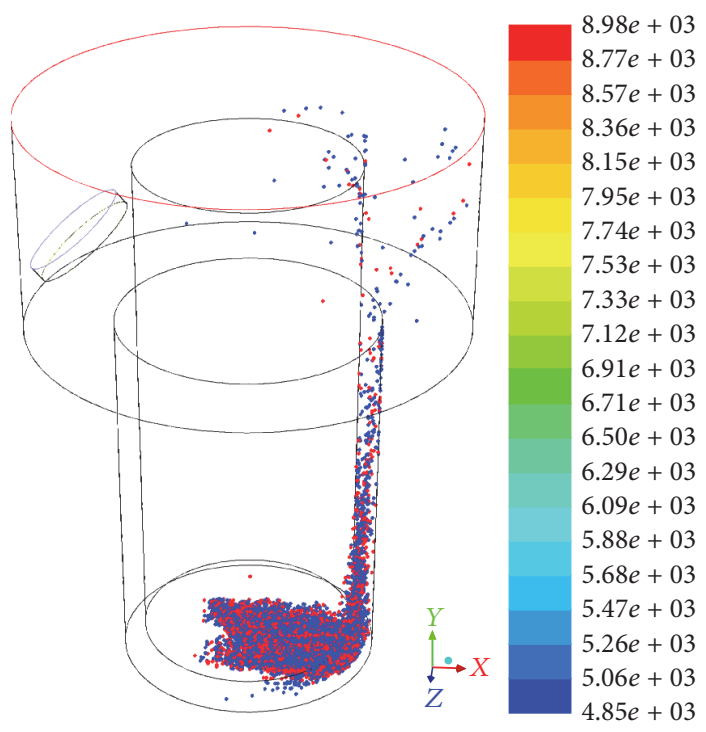

(c) Debris distribution

Figure 17: Schematics of gap flow field with flushing at $5 \mathrm{~m} / \mathrm{s}$ and $3.5 \mathrm{~mm}$ deep hole.

resistance and has insufficient pressure to take away the debris from the gap.

\section{Experiment Results and Discussion}

The experiment is carried out on a self-made EDM machine. The detailed parameters applied are listed in Table 2. After the machining, the microscope is utilized to observe the cross sections of machined hole. Experimental results are shown in Figures 24 and 25.

Figures 24(a) and 24(b) present $0.5 \mathrm{~mm}$ deep hole and $2 \mathrm{~mm}$ deep hole without flushing. The cross section image of hole is basically axial symmetric about the axis of the hole. The burn marks can be seen clearly, just as shown in the white cycle in Figure 24. The burn marks are generated by large quantity of debris remained at bottom gap. The existence of burn marks indicates that the fluid disturbance induced by tool movement can hardly remove the debris from the bottom gap, of which the concentrated discharge is created between the debris and the workpiece repeatedly. The concentrated discharge could cause the continuous melt and recast, which results in no material removed from the workpiece. The position of burn marks locates at the bottom of the hole, which corresponds well with the simulation results in 


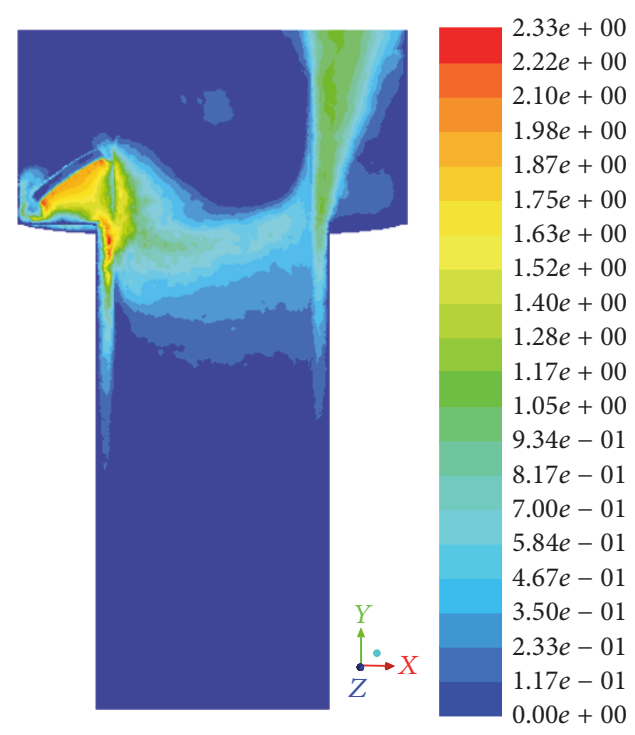

(a) Velocity field

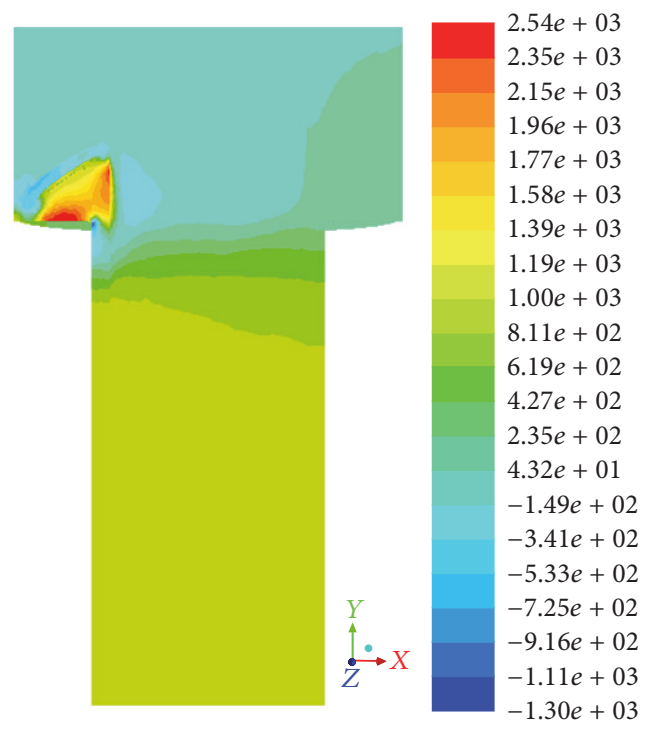

(b) Pressure field

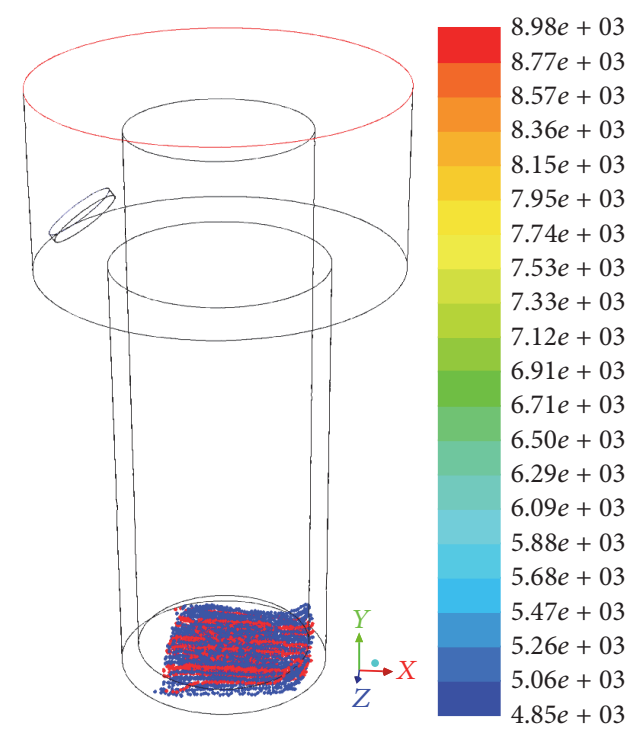

(c) Debris distribution

Figure 18: Schematics of gap flow field with flushing at $2 \mathrm{~m} / \mathrm{s}$ and $5 \mathrm{~mm}$ deep hole.

TABLE 2: Continuous discharge simulating parameters.

\begin{tabular}{lc}
\hline Parameter & Description \\
\hline Maintaining voltage $(U)$ & $15 \mathrm{~V}$ \\
Peak current $\left(I_{p}\right)$ & $0.8 \mathrm{~A}$ \\
Dielectric fluid & Deionized water \\
Tool material & Red copper \\
Workpiece material & $\mathrm{TC} 4$ \\
Tool velocity & $0.01 \mathrm{~m} / \mathrm{s}$ \\
Tool diameter & $2 \mathrm{~mm}$ \\
Depth $(\mathrm{mm})$ & $0.5,2.0,3.5,5.0$ \\
Flushing velocity $(\mathrm{m} / \mathrm{s})$ & 0,2 \\
\hline
\end{tabular}

Figures 4 and 5. With the increase of hole depth, the probability of debris removal decreases, which increases the burn mark area. Such results correspond well with the simulation results in Figures 4 and 5.

Figure 25(a) presents the result of $0.5 \mathrm{~mm}$ deep with side flushing. Obviously, Figure 25(a) has no burn mark on the machined surface, which means that the debris at bottom gap could be effectively flushed out. The area of burn mark in Figure 25(b) is smaller than that in Figure 24(b), which indicates that the debris is easily carried away by the fluid flushing. Besides, in the case of hole depth with 0.5 and $2.0 \mathrm{~mm}$, with and without flushing, both cross sections of the walls are symmetric, which indicates that the debris distributed at the bottom is uniform. 


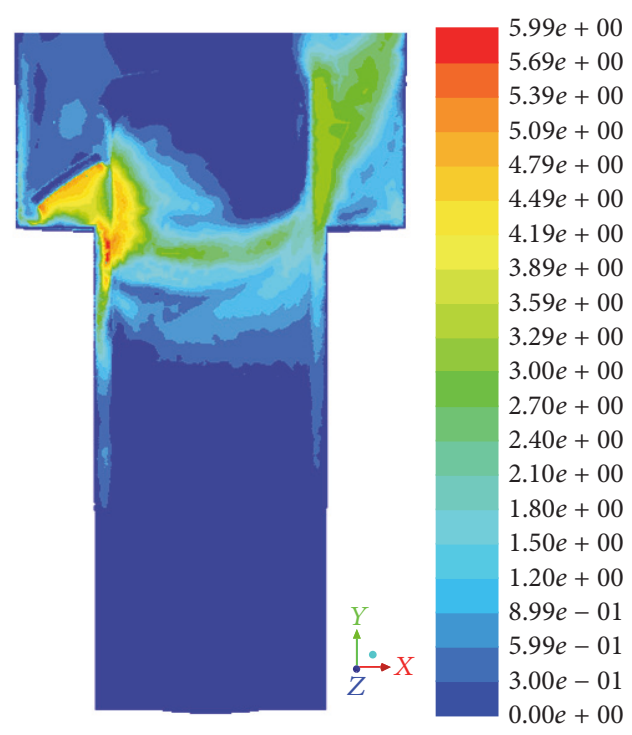

(a) Velocity field

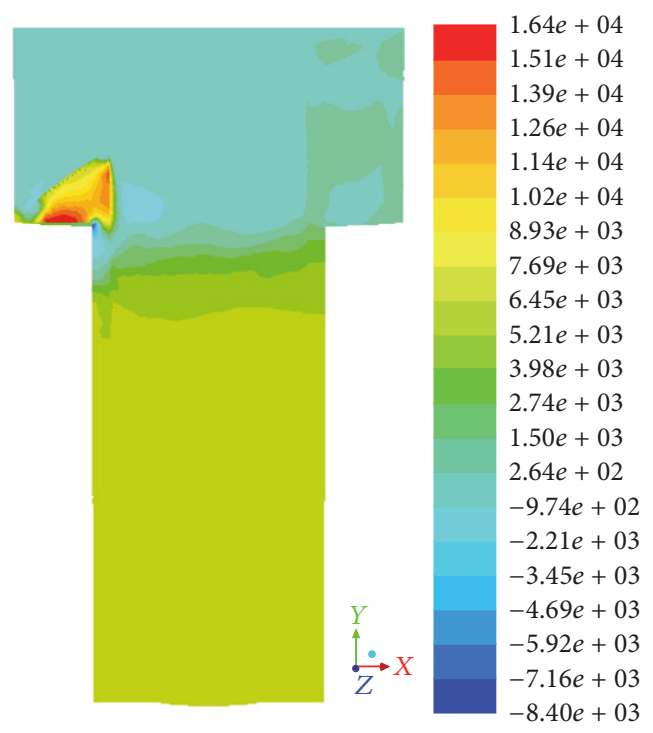

(b) Pressure field

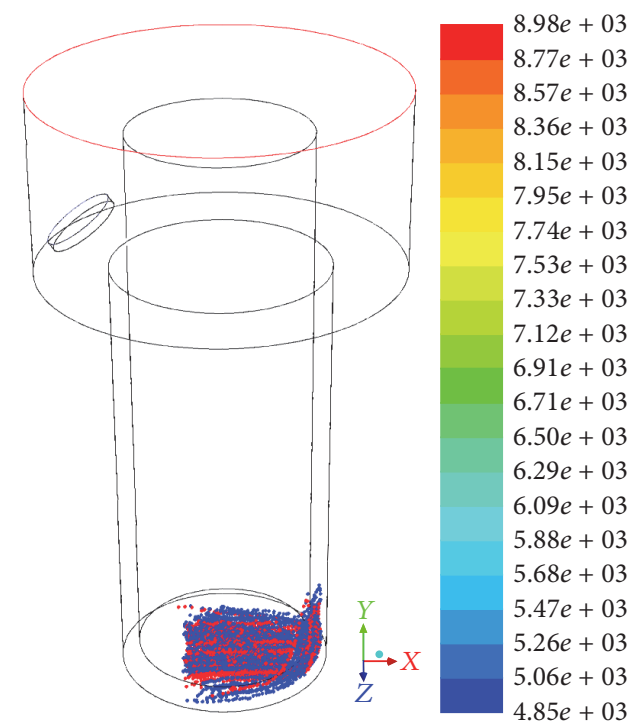

(c) Debris distribution

FIGURE 19: Schematics of gap flow field with flushing at $5 \mathrm{~m} / \mathrm{s}$ and $5 \mathrm{~mm}$ deep hole.

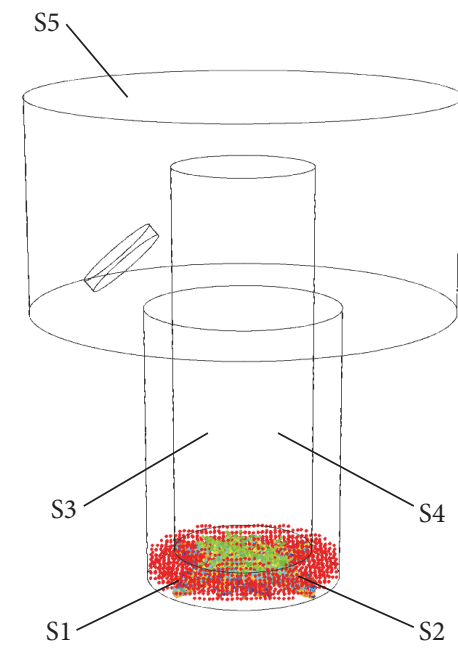

(a) Zone view

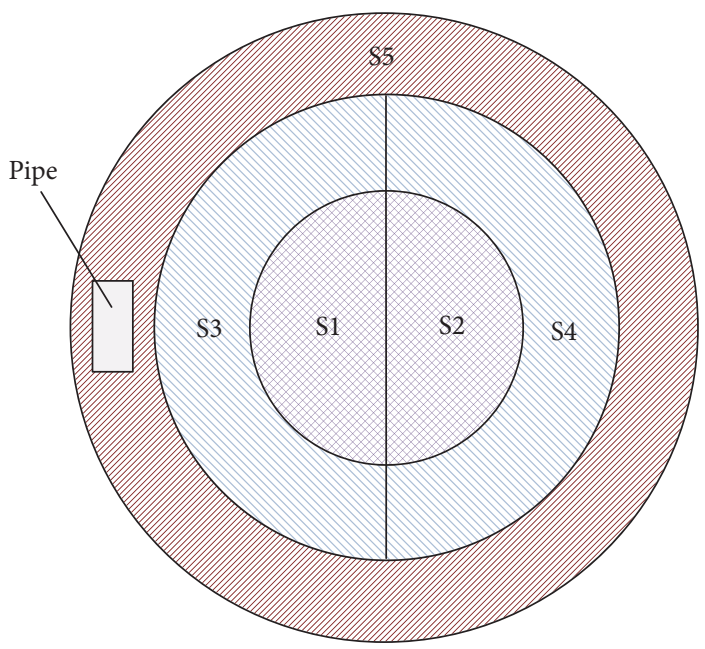

(b) Bird view

Figure 20: Schematics of debris domain (moves from the top to the bottom). 

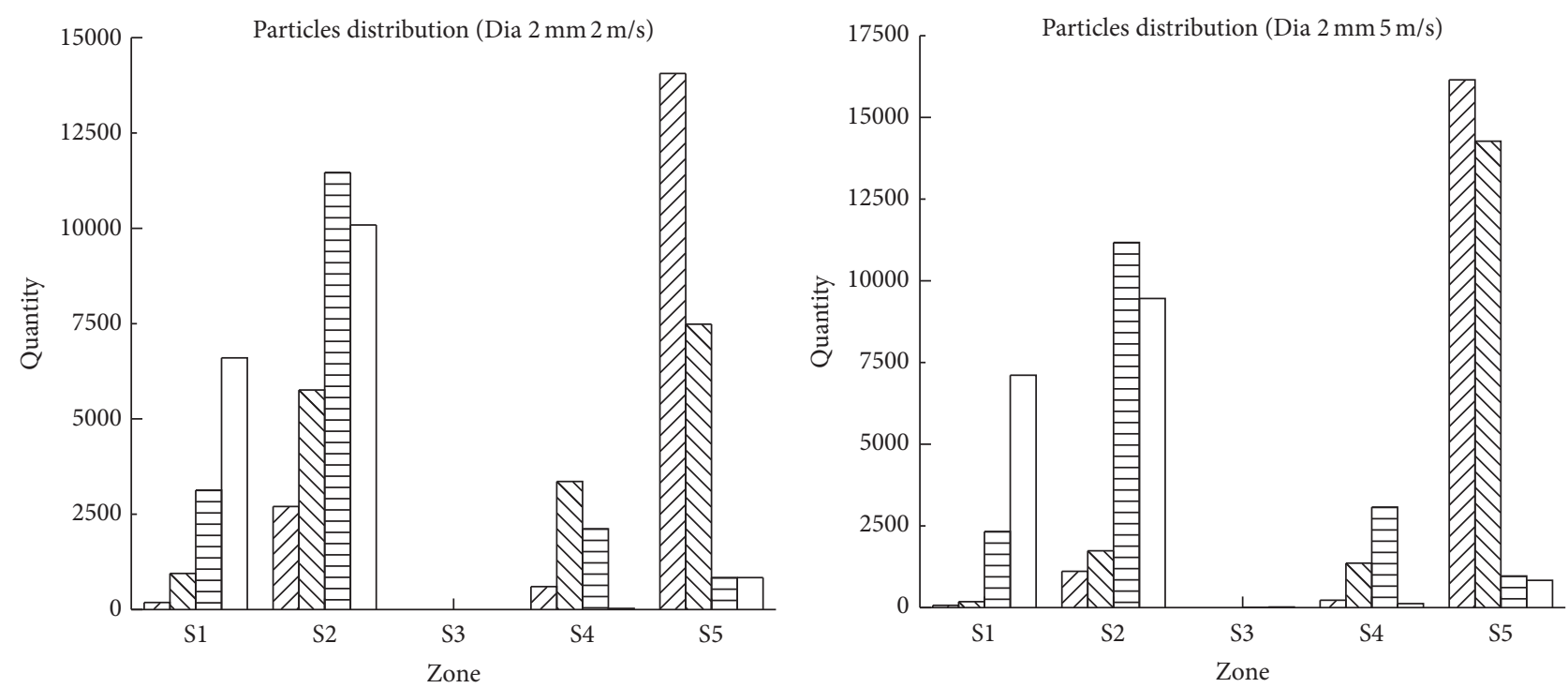

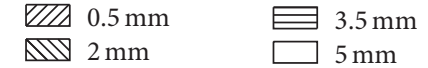

(a)

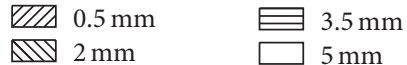

(b)

FIGURE 21: Impact of depths on the debris distribution.

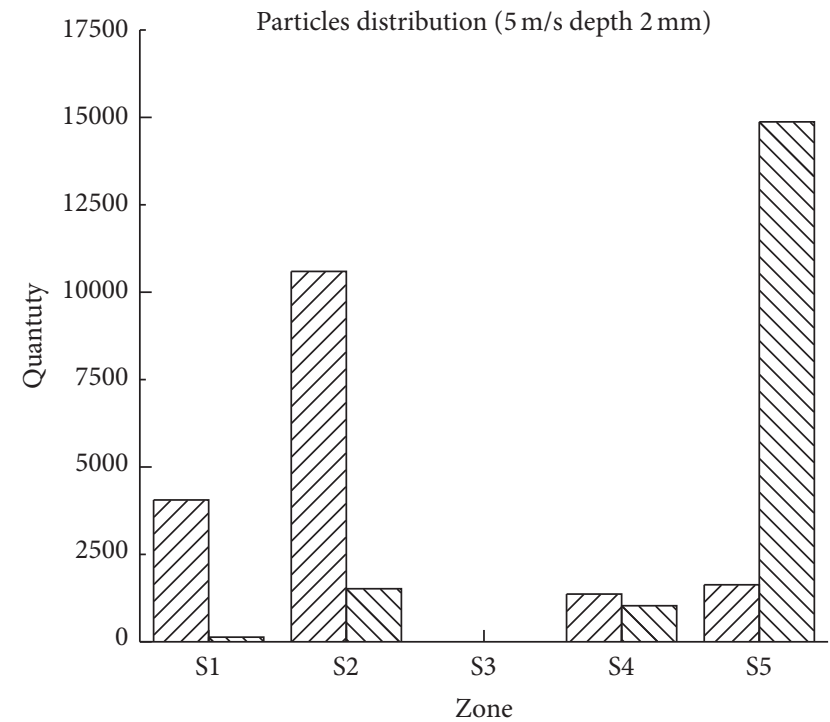

UIJ Dia $1 \mathrm{~mm}$ MIV Dia $2 \mathrm{~mm}$

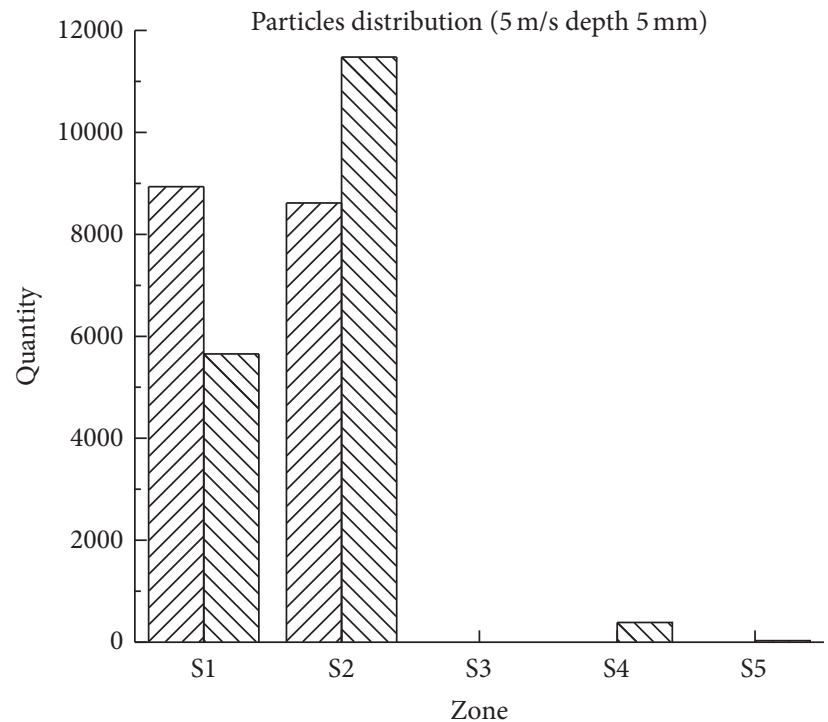

ZII Dia $1 \mathrm{~mm}$ MIV Dia $2 \mathrm{~mm}$

(a)

(b)

FIGURE 22: Impact of diameters on the debris distribution.

For $3.5 \mathrm{~mm}$ deep hole, the burn mark appears at the lower right corner of the hole, which illustrates that most debris accumulates at the lower right corner under the influence of flushing, as shown in Figure 25(c). The accumulated debris can increase the electrical conductivity of dielectric. So the secondary discharges are easily created between the sides of tool and right wall before the energy is fully reloaded, which causes the burn marks at bottom of hole. Besides, the inclination of right wall of hole is larger than that of left one. During the process of debris flushed out from side gap, the 


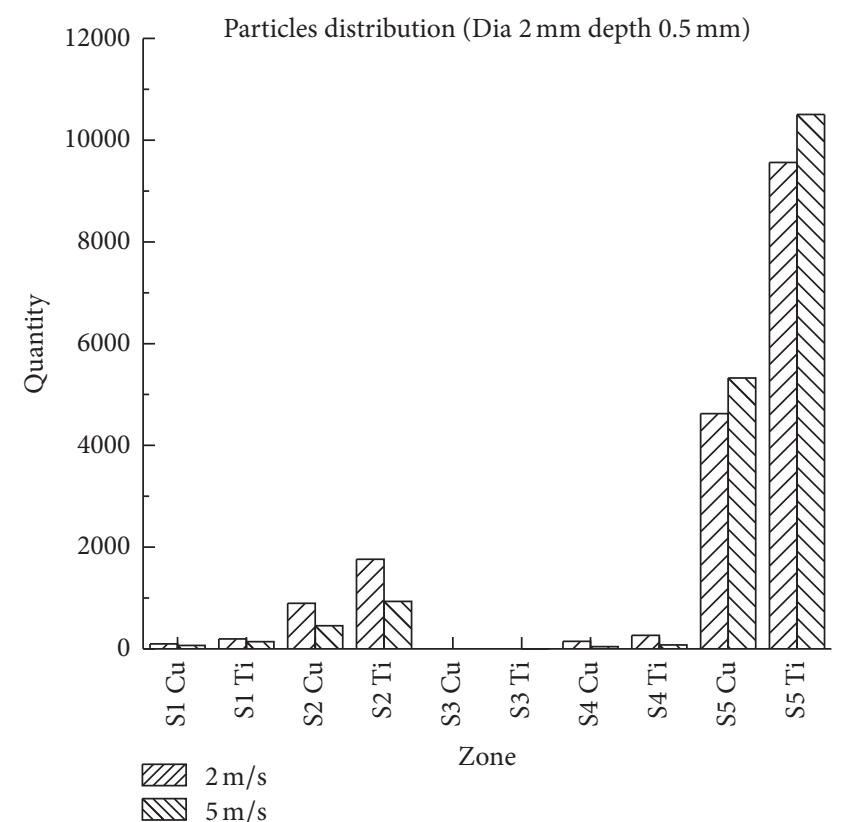

(a) Impact of flushing velocities

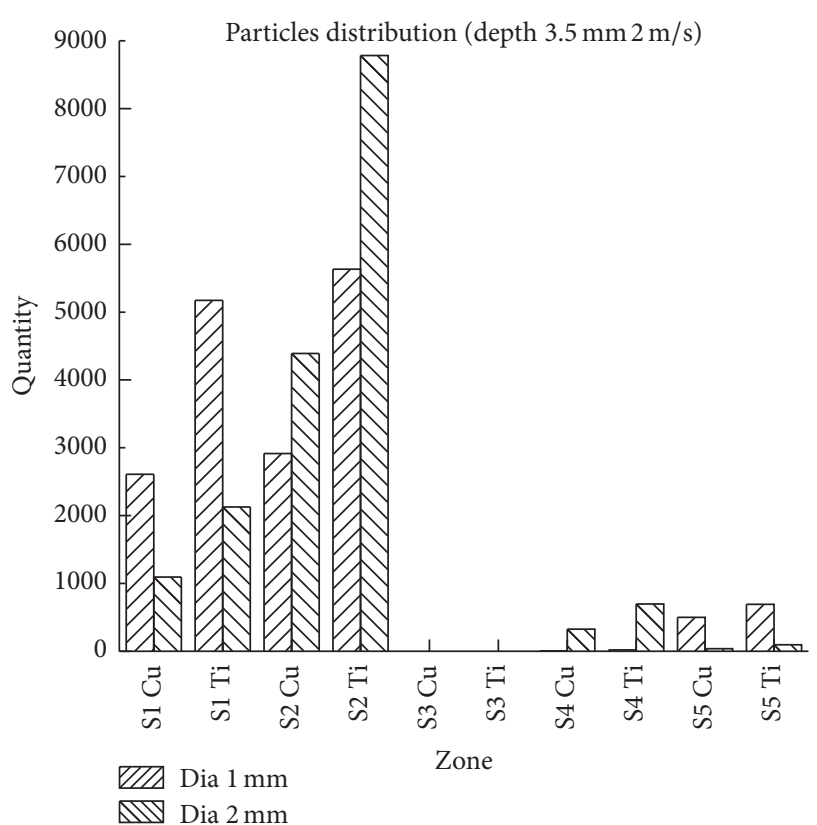

(b) Impact of tool diameters

FIGURE 23: Debris statistical distribution of $\mathrm{Cu}$ and $\mathrm{Ti}$ in different conditions.

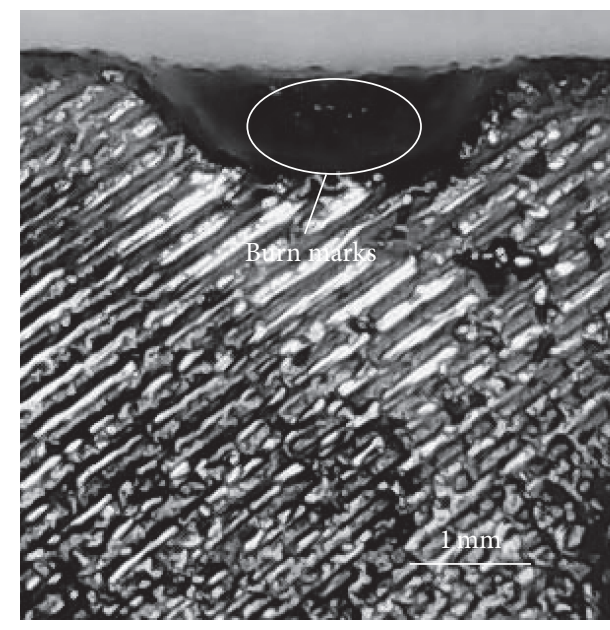

(a) $0.5 \mathrm{~mm}$ deep hole

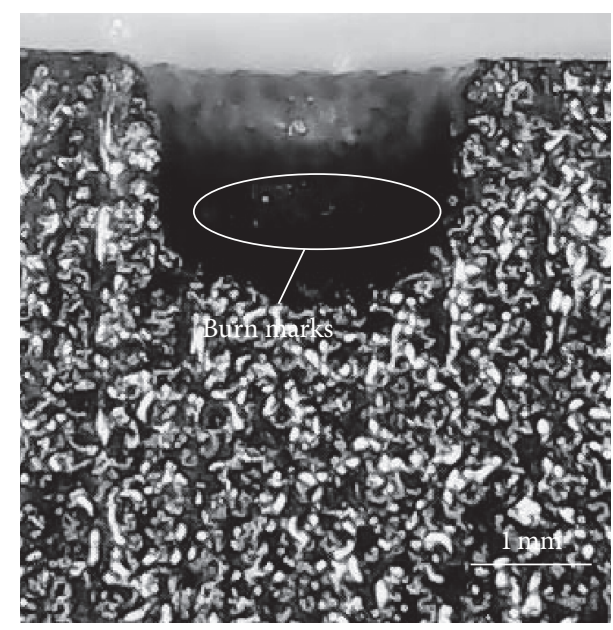

(b) $2 \mathrm{~mm}$ deep hole

FIGURE 24: The cross section image of machined holes without flushing.

secondary discharge happens between the right side of tool and wall, which causes the unsymmetrical wall, just as shown in Figure 25(c). These experiment results correspond well with the mathematical model and distribution simulation results in Figures 16 and 17.

When processing $5 \mathrm{~mm}$ deep hole with $2 \mathrm{~mm}$ tool diameter, as shown in Figure 25(d), the upper wall of the hole has an obvious inclination on the right side, the reason is similar as above, but the lower part of two walls is nearly symmetrical. It is because the hole is too deep that nearly no fluid is injected into the deep gap and debris is distributed uniformly at the bottom. Therefore, the lower parts of walls are evenly worn out. This phenomenon is in accordance with the simulation results of Figures 18 and 19. In a word, if the ratio of depth to diameter exceeds 2, side flushing is not suitable for processing, as the debris removal rate is of limited effect, which can result in a very low machining efficiency; other flushing methods such as internal flushing or rotating tool machining for small hole EDM are recommended. 


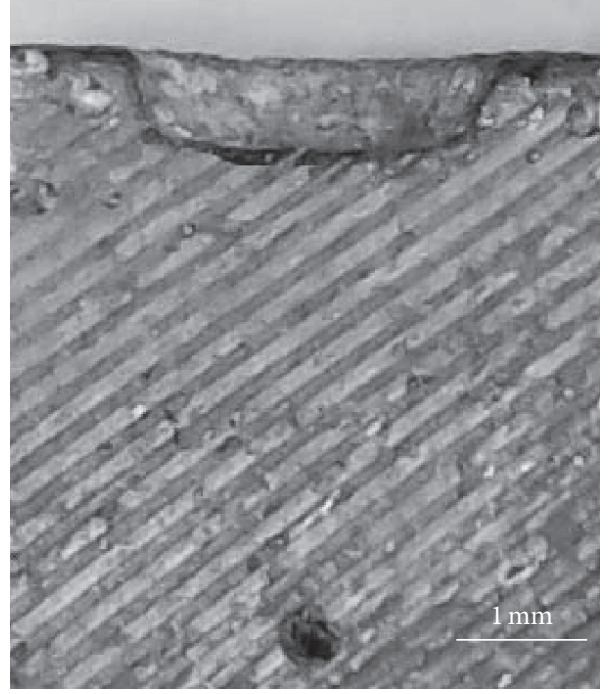

(a) $0.5 \mathrm{~mm}$ deep hole

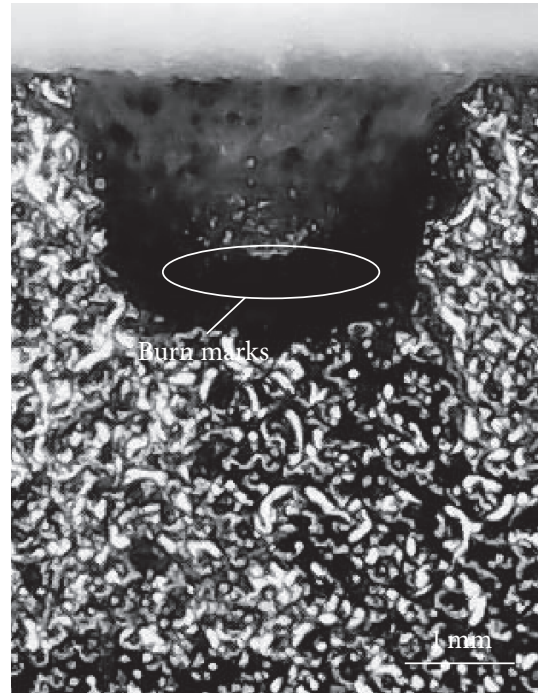

(b) $2 \mathrm{~mm}$ deep hole

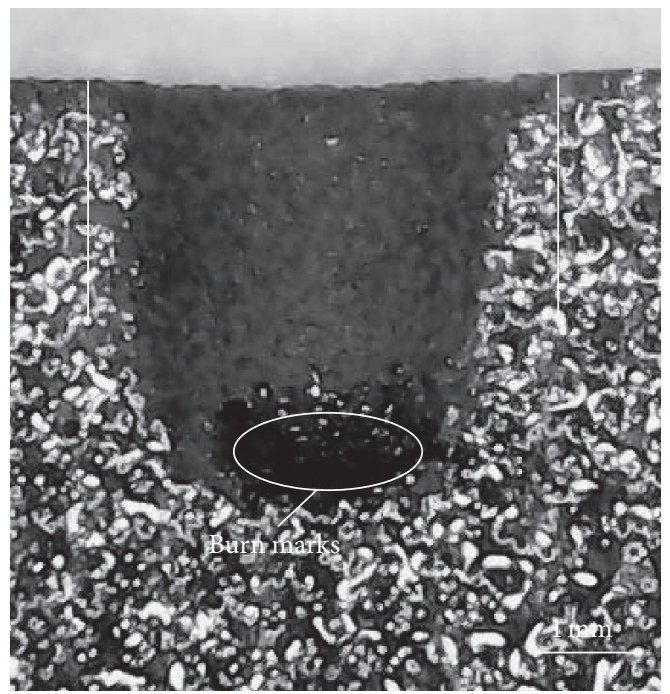

(c) $3.5 \mathrm{~mm}$ deep hole

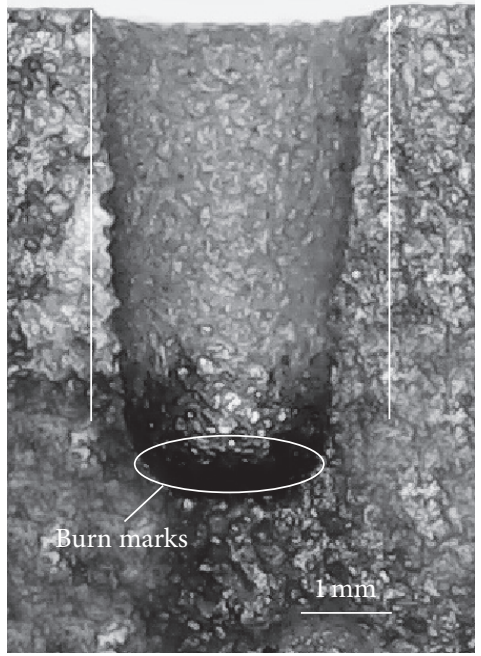

(d) $5 \mathrm{~mm}$ deep hole

FIGURE 25: The cross section image of machined holes with flushing.

\section{Conclusions}

This paper researches the effect law of machining parameters to the gap flow field and debris movement. Besides the disturbation induced by self-adaptive movement on the gap flow is considered. Based on the solid-liquid two-phase flow, a mathematical model of fluid in gap flow field and debris movement is derived. The methods of smoothing and remeshing are also considered. The real situation of continuous discharging and debris generating is taken into account, a simulation model of the small hole gap flow field in EDM and debris distribution was established, 3D model simulates the influence of tool movement, machining depth, flushing velocity, and tool diameter on interelectrode gap flow field, and debris distribution was analyzed; furthermore, the mathematical model was verified by the experimental results. The conclusions are listed as follows:

(1) During the machining, the self-adaptive movement of tool can generate disturbance to the machining region, which is positive for the debris removal. However, in the case of deep hole machining, the impact of flushing is of limited effect.

(2) The depth of the hole, flushing velocity and tool diameter influence the gap flow field and debris distribution. Normally, with the increasing depth of machining hole, the fluid velocity declines at the bottom gap, and the debris is not easily removed. With the increase of flushing velocity, the fluid at the bottom takes more debris away. A large diameter 
is beneficial for reducing the resistance of fluid and debris removal. But when the depth of the machined hole increases to a certain degree, whose depth to diameter exceeds 3 , the impact of flushing velocity and tool diameter on debris removal reduces obviously, which results in a lot of debris at the bottom. The side flushing is of limited effect.

(3) During the small deep hole machining process, the cross section appearance of side walls as well as positions of the burn mark is in accordance with the simulating results of debris distribution and movement, which proves the effectiveness of mathematical model and simulation model.

\section{Conflicts of Interest}

The authors declare that they have no conflicts of interest.

\section{Acknowledgments}

The financial support by National Natural Science Foundation of China under Grant no. 51405058, Program for Liaoning Excellent Talents in University under Grant no. LR2015012, and Talent Special Foundation of Dalian City under Grant no. 2016RQ054 is acknowledged.

\section{References}

[1] T. Muthuramalingam and B. Mohan, "A review on influence of electrical process parameters in EDM process," Archives of Civil and Mechanical Engineering, vol. 15, no. 1, pp. 87-94, 2015.

[2] J. DBhaghi, M. S. Bohat, V. P. Kalsi et al., "A review on effect of EDM parameters on die sinking EDM," Trends in Mechanical Engineering \& Technology, vol. 5, no. 1, pp. 26-30, 2015.

[3] F. N. Leão and I. R. Pashby, "A review on the use of environmentally-friendly dielectric fluids in electrical discharge machining," Journal of Materials Processing Technology, vol. 149, no. 1-3, pp. 341-346, 2004.

[4] W. Koenig, R. Weill, R. Wertheim et al., "The flow fields in the working gap with electro-discharge-machining," Annals of the CIRP, vol. 25, no. 1, pp. 71-76, 1977.

[5] T. Masuzawa, X. Cui, and N. Taniguchi, "Improved jet flushing for EDM," CIRP Annals_Manufacturing Technology, vol. 41, no. 1, pp. 239-242, 1992.

[6] H. Takeuchi and M. Kunieda, "Relation between debris concentration and discharge machining," Denki Kako Gakkaishi, no. 12, pp. 17-22, 2007.

[7] P. Allen and X. Chen, "Process simulation of micro electrodischarge machining on molybdenum," Journal of Materials Processing Technology, vol. 186, no. 1-3, pp. 346-355, 2007.

[8] Y. Q. Wang, M. R. Cao, S. Q. Yang, and W. H. Li, "Numerical simulation of liquid-solid two-phase flow field in discharge gap of high-speed small hole EDM drilling," Advanced Materials Research, vol. 53-54, pp. 409-414, 2008.

[9] B.-C. Xie, Y.-K. Wang, Z.-L. Wang, and W.-S. Zhao, "Numerical simulation of titanium alloy machining in electric discharge machining process," Transactions of Nonferrous Metals Society of China, vol. 21, no. 2, pp. s434-s439, 2011.
[10] S. Cetin, A. Okada, and Y. Uno, "Electrode jump motion in linear motor equipped die-sinking EDM," Journal of Manufacturing Science and Engineering, Transactions of the ASME, vol. 125, no. 4, pp. 809-815, 2003.

[11] J. Wang, F. Z. Han, G. Cheng, and F. Zhao, "Debris and bubble movements during electrical discharge machining," International Journal of Machine Tools and Manufacture, vol. 58, no. 7, pp. 11-18, 2012.

[12] W. Kong, C. Guo, and X. Zhu, "Simulation analysis of bubble motion under ultrasonic assisted Electrical Discharge Machining," in Proceedings of the 3rd International Conference on Machinery, Materials and Information Technology Applications (ICMMITA '15), vol. 1, pp. 1728-1731, Qingdao, China, November 2015.

[13] S. A. Mastud, N. S. Kothari, R. K. Singh, and S. S. Joshi, "Modeling debris motion in vibration assisted reverse micro electrical discharge machining process (R-MEDM)," Journal of Microelectromechanical Systems, vol. 24, no. 3, pp. 661-676, 2015.

[14] S. A. Mullya and G. Karthikeyan, "Dielectric flow observation at inter-electrode gap in micro-electro-discharge-milling process," Proceedings of the Institution of Mechanical Engineers, Part B: Journal of Engineering Manufacture, 2016.

[15] P. T. Eubank, M. R. Patel, M. A. Barrufet, and B. Bozkurt, "Theoretical models of the electrical discharge machining process. III. the variable mass, cylindrical plasma model," Journal of Applied Physics, vol. 73, no. 11, pp. 7900-7909, 1993.

[16] R. M. Bruce, F. Y. Donald, and H. O. Theodore, Fundamentals of Fluid Mechanics, John Wiley \& Sons, 2009.

[17] S. Hayakawa, M. Yuzawa, M. Kunieda et al., "Time variation and mechanism of determining power distribution in electrodes during EDM process," International Journal of Electrical Machining, no. 6, pp. 19-26, 2001.

[18] Y. Liu, W. C. Zhang, S. F. Zhang, and Z. H. Sha, "The simulation research of tool wear in small hole EDM machining on titanium alloy," Applied Mechanics and Materials, no. 624, pp. 249-254, 2014. 

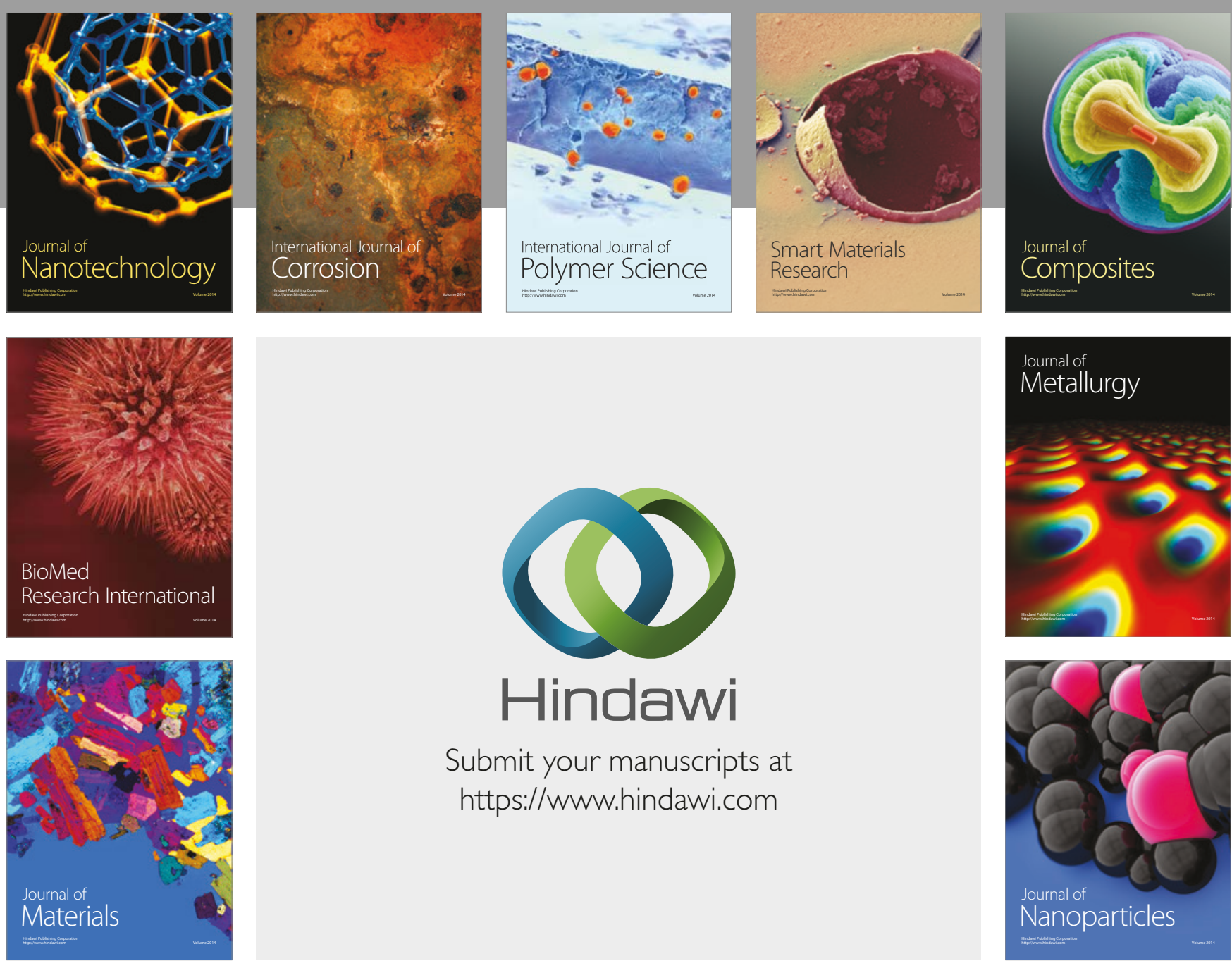

\section{Hindawi}

Submit your manuscripts at

https://www.hindawi.com
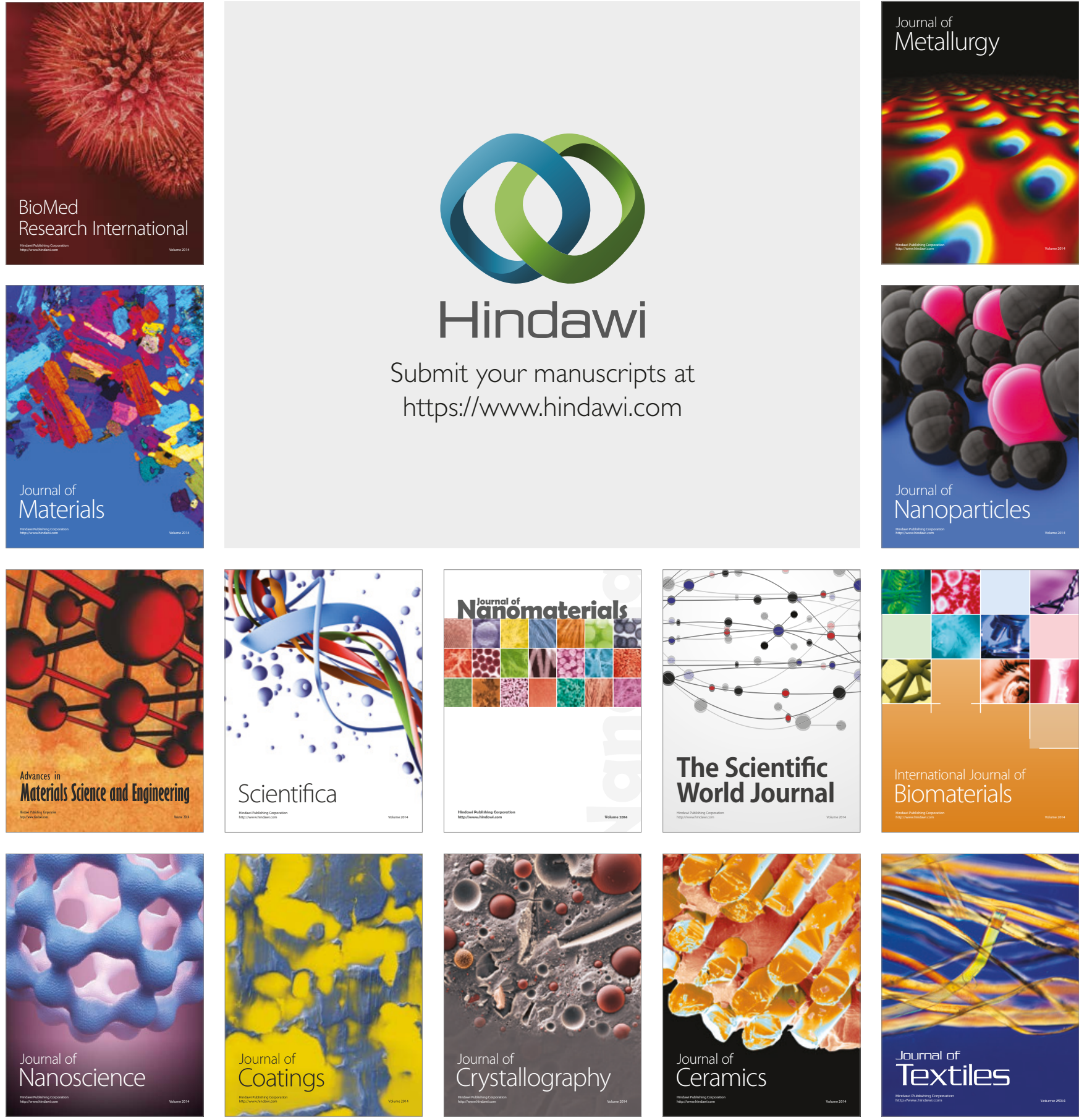

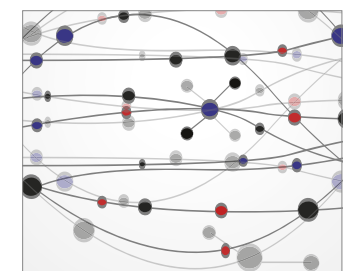

The Scientific World Journal
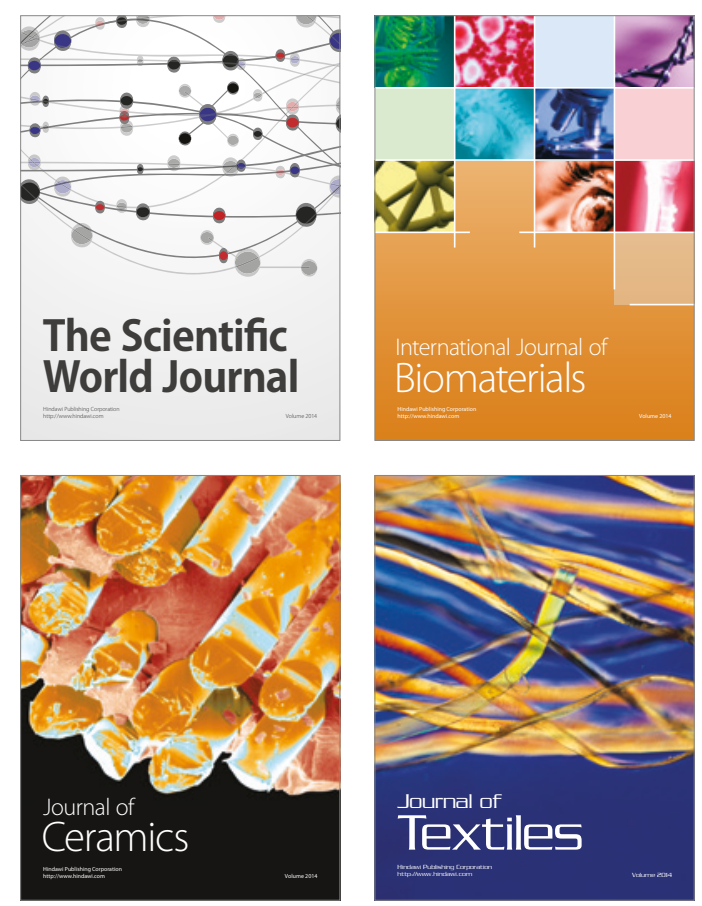